Document downloaded from:

http://hdl.handle.net/10251/160076

This paper must be cited as:

Tormos, B.; Novella Rosa, R.; Gómez-Soriano, J.; García-Barberá, A.; Tsuji, N.; Uehara, I.; Alonso, M. (2019). Study of the influence of emission control strategies on the soot content and fuel dilution in engine oil. Tribology International. 136:285-298.

https://doi.org/10.1016/j.triboint.2019.03.066

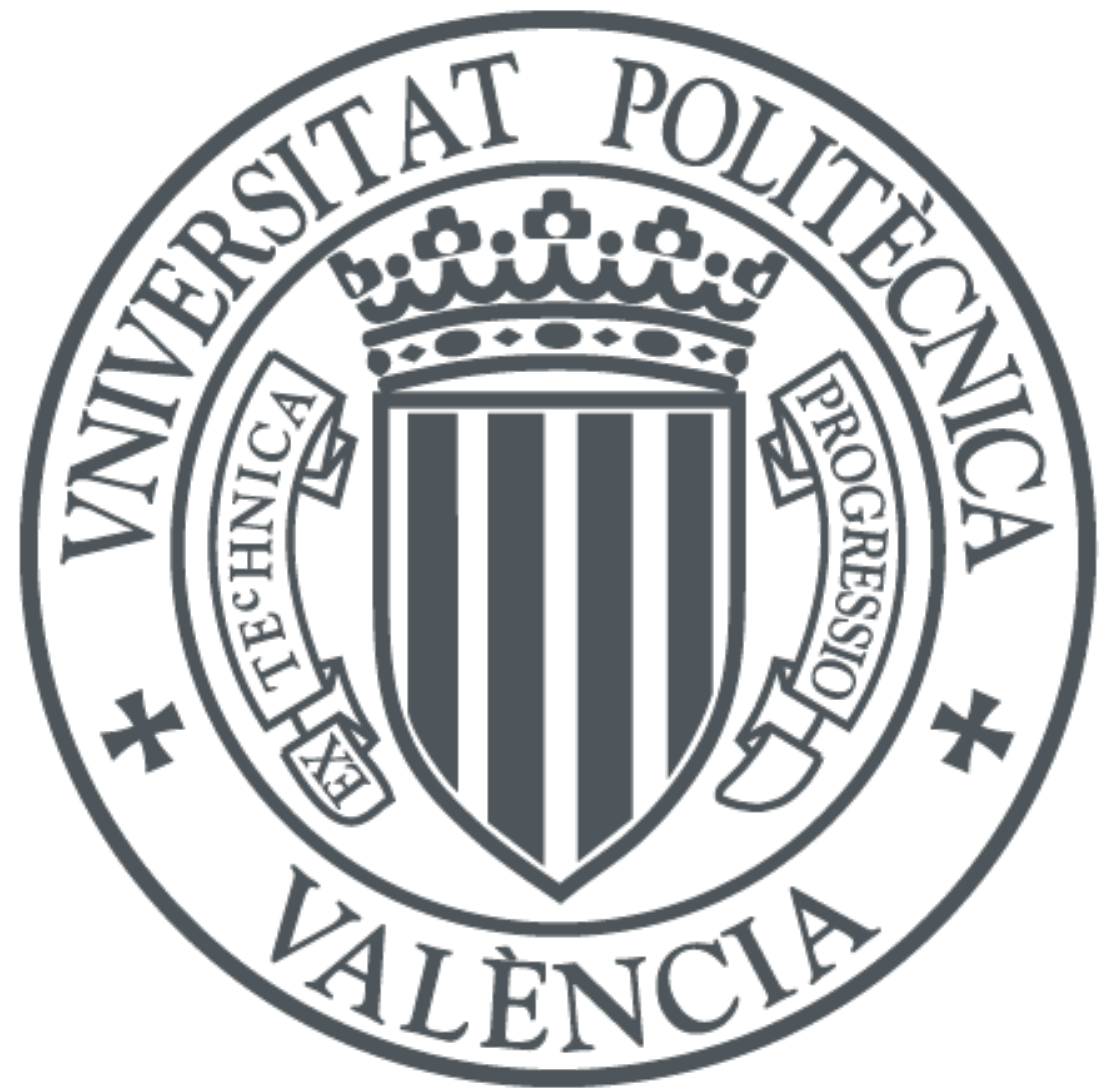

The final publication is available at

https://doi.org/10.1016/j.triboint.2019.03.066

Copyright Elsevier

Additional Information 


\title{
Study of the influence of emission control strategies on the soot content and fuel dilution in engine oil
}

\author{
Bernardo Tormos ${ }^{\mathrm{a}, *}$, Ricardo Novella ${ }^{\mathrm{a}}$, Josep Gomez-Soriano ${ }^{\mathrm{a}}$, Antonio García-Barberáa ${ }^{\text {, }}$ \\ Naohide Tsuji ${ }^{\mathrm{b}}$, Isshou Uehara ${ }^{\mathrm{b}}$, Marcos Alonso $^{\mathrm{c}}$ \\ ${ }^{a}$ CMT - Motores Térmicos, Universitat Politècnica de València, Camino de Vera, 46022 Valencia, Spain \\ ${ }^{b}$ Nissan Motor Co., Ltd., 560-2 Okatsukoku, Atsugi-shi, Kanagawa 243-0192, Japan \\ ${ }^{c}$ Nissan Technical Centre Europe-Spain, Zona Franca Sector B C/3 77-111, 08040 Barcelona, Spain
}

\begin{abstract}
The engine oil contamination by both particulate matter (PM) and fuel is becoming an important problem since strategies to control pollutant emissions in internal combustion engines (ICE) significantly increase their presence in engine oil. As a consequence, the engine oil loses its tribological properties compromising engine lubrication and leading to potential problems in engine such as wear, corrosion, etc. For that reason, the study of the oil degradation and contamination due to these strategies have a special interest to the engine manufacturers and engine oil formulators. In this paper, the engine oil soot content and fuel dilution is analysed under real engine conditions. The study is addressed from two different but complementary points of views. First, on-line measurements at several engine operating conditions are performed in order to further understand how the soot generation correlates with the oil soot content and other derived problems on oil performance. Then, experimental data available after the experimental campaign is used to calibrate a numerical model, based on Computational Fluid Dynamics (CFD), that estimate the amount of soot particles settled in the engine oil. Results show that soot particles are more present in oil when operating high load-speed conditions and during the Diesel Particulate Filter (DPF) regeneration cycles. Regarding the fuel dilution, delayed post-injections are critical since they significantly increase the amount of fuel in the engine oil. Numerical results also show the relationships between the soot particles generated during combustion and the amount of soot in engine oil, giving an enhanced comprehension of soot-in-oil deposition mechanisms.
\end{abstract}

Keywords: ICE emissions, soot in oil, oil fuel dilution, oil analysis, control strategies

\section{Introduction}

In recent years environmental issues have become of more and more concern worldwide. In order to reduce pollutant and greenhouse gas exhaust, particularly $\mathrm{CO}_{2}$ emissions, a series of emission standards have been mandated almost all around the world [1, 2. That different standards and laws define levels of pollutant emissions that engine manufacturers (OEMs) must obey [3] 7 . Consequently, OEMs design new technologies for achieving emissions reductions. Main technologies grouped attending engine type can be roughly summarized: regarding gasoline engines, to fulfil the exhaust emissions levels some solutions have been implemented such as downsizing and turbo-charging. Meanwhile, diesel engines require more complex efforts. In this case, different solutions have been focused from several point of views: gas exchange processes, injection systems and after treatment devices. These common after treatment devices are: exhaust gases recirculation (EGR) [8 14, diesel particulate filter (DPF) [15, 16] and the selective catalysts systems also known as SCR (Selective Catalytic Reduction) [17, 18.

\footnotetext{
*Corresponding author. Tel.: +34 963877 650, email: betormos@mot.upv.es
} 
The EGR goal is the reduction of nitrogen oxides $\left(\mathrm{NO}_{\mathrm{x}}\right)$ emissions in diesel engines, the process involves the recirculation of a portion of exhaust gases to the intake system to dilute the fresh mixture (air and fuel) to reduce the maximum combustion temperatures. These low temperatures avoid the generation of $\mathrm{NO}_{\mathrm{x}}$ but provide a boost in soot production and as well as a further penalty arising from the recirculation of the exhaust emissions $19+21$.

The Diesel Particulate Filter (DPF) typical definition is a device which physically captures diesel carbon particulates preventing their discharge from the tailpipe. Some filters are single-use but mainly are designed to burn off the accumulated particulate either passively, through the use of a catalyst, or by active means, which heats the filter to soot combustion temperatures. This is known as filter regeneration. One typical process for DPF regeneration consists of a thermal treatment where the temperature of exhaust gases increase up to $650^{\circ} \mathrm{C}$ (approx.) using delayed injections 22 .

Selective catalytic reduction ( $\mathrm{SCR}$ ) is a means of converting $\mathrm{NO}_{\mathrm{x}}$ with the aid of a catalyst into diatomic nitrogen $\left(\mathrm{N}_{2}\right)$, water $\left(\mathrm{H}_{2} \mathrm{O}\right)$ and tiny amounts of carbon dioxide $\left(\mathrm{CO}_{2}\right)$. A gaseous reducing agent, typically anhydrous ammonia, aqueous ammonia or urea - otherwise known as Diesel Exhaust Fluid (DEF) - , is added to a stream of exhaust gas and adsorbed onto a catalyst.

As it has been mentioned, those after treatment devices solve some of the emissions problems but compromise certain aspects related to the engine lubrication. The use of EGR lead to higher levels of soot in the engine oil [23, 24] while the DPF regeneration process increases the oil degradation due to the raised temperatures inside the cylinder. In addition, the configuration of late fuel injections also tends to worsen the combustion stability and consequently, to increase both the soot levels in the combustion chamber and the fuel dilution in engine oil. That higher level of soot in the combustion chamber is translated to higher exhaust particulate content and/or higher presence of soot-in-oil ( $\mathrm{SiO})$.

When the fuel is not completely burned off during combustion, it can pass down (to the crankcase) by blow-by, mixing with the engine oil [18]. Another way that can generate fuel dilution [25] is when fuel droplets condensed at the cooler parts of the combustion chamber leak trough the piston rings and they fuse with the bulk engine oil in the crankcase [26. A major problem of the fuel dilution is that it provokes the lubricant breakdown [27, 28. The fuel reduces the engine oil viscosity and it causes the lubrication film thickness to weaken and to be less capable of preventing the contact between the metal surfaces of the lubricated engine areas. Moreover, there are other relevant problems derived from the presence of fuel in the engine oil: reduction of detergent additives effectiveness, higher engine oil volatility (engine oil consumption may increase due to this) and acceleration of oil oxidation processes [29].

Furthermore, soot particles induce oil to behave differently. While part of the soot generated will be expelled by exhaust gases to the atmosphere, some particles impinge on the oil film of the cylinder wall and they pass to the engine oil trough the piston rings. As a result, the soot is quickly mixed with the bulk oil and it circulates throughout the engine. In this case, the engine oil soot level is a relevant aspect since it changes the tribo-chemical properties of engine oil [26, 30]. It interferes with the additives and depletes them: soot competes with the engine oil for the adsorption on the surfaces and restricts the tribofilm generation. Also, the soot particles are capable of absorbing additives (anti-wear, dispersant, etc.), causing an efficiency reduction [31, 32, an increase of the viscosity [33, 34], an abrasive wear effect generation [35] and an increased engine oil thickening/gelation.

As a consequence, the new strategies for improving pollutant emission levels can lead to higher engine oil degradation and contamination by both soot and fuel dilution, that in turn, may result in potential engine failures due to a deficient lubrication of the moving components and the presence of particular contaminants that may also damage these elements [36. In view of the trend of increasing restrictions in diesel engines, the use of the aforementioned post-treatment techniques will be come more common and, consequently, the study of those negative effects in the engine operation is becoming determinant.

This study was proposed to assess the effects of different DPF regeneration strategies on a medium-duty diesel engine in terms of engine oil soot content and fuel dilution. In this way, the main objective of this paper focuses on determining how both aspects change as the operating settings are modified. A combination of experimental and numerical techniques were employed to analyse both global trends and local features in depth, thereby allowing a better understanding of all involved phenomena. 


\section{Experimental tools}

\subsection{Engine specifications}

The engine used for the experimental measurements was a 4-cylinder and 4-stroke compression-ignition (CI) medium-duty Direct Injection (DI) engine. This engine is equipped with a common-rail injection system and a turbochared/intercooler air loop system. The main engine characteristics are shown in Table 1

Table 1: Main specifications of the engine.

\begin{tabular}{ll}
\hline Engine type & CIDI engine \\
\hline Combustion chamber & Re-entrant \\
Cylinders & 4 \\
Unitary displacement [ $\left.\mathrm{cm}^{3}\right]$ & 738.3 \\
Bore x Stroke [mm] & $96.0 \times 102.0$ \\
Bowl width [mm] & 62.4 \\
Valves [valves/cylinder] & 4 \\
Connecting rod length [mm] & 154.5 \\
Geometric compression ratio [-] & 15.5 \\
Maximum effective power @ 3600 rpm [kW] & 111.3 \\
Maximum effective torque @ 2000rpm [Nm] & 350.0 \\
\hline
\end{tabular}

\subsection{Engine test cell}

Experimental activities, including all measurements, acquisition system design and engine instrumentation were performed in a full instrumented test cell at laboratory 8P of CMT-Motores Térmicos located at Universitat Politècnica de València [37, 38. Figure 1 summarizes all auxiliary instrumentation systems to monitor and control the engine operation. The engine was coupled to an asynchronous electric dynamometer Horiba DYNAS3, controlled by the commercial software Stars.

Several piezo-resistive PMA40 sensors were located in the engine to measure all relevant operating pressures. In-cylinder pressure signal was measured using a Kistler 6055Bsp glow-pug piezoelectric sensor while the Yokogawa DL850V device was used to record all high frequency signals. Additional sensors were installed in the engine to measure other relevant parameters. K-type thermocouples were installed to register the temperature of all fluids in the engine (engine oil, coolant, intake and exhaust flows). Air and fuel flows were controlled by the Sensyflow ABB FMT700-P and by the Horiba FQ-2100DP device, respectively. 40 piezoresistive PMA sensors were distributed in the engine to measure pressure parameters.

The most relevant combustion parameters i.e. indicated mean effective pressure (IMEP), combustion phasing angles, Heat Release Rate (HRR), thermodynamic conditions and wall temperatures required for the numerical simulations were calculated from the in-cylinder pressure considering some simplifications to the energy equation [39, 40. This calculation assumes uniform pressure and temperature throughout the whole combustion chamber volume to accurately estimate the energy released by combustion, thereby details about the local thermochemical properties are not provided.

\subsection{Engine soot measurements}

Soot measurements were performed at two different points of the engine. Tailpipe Smoke emissions, in Filter Smoke Number (FSN) units, were measured by a Smokemeter AVL 451S and translated to soot particles with the correlation proposed by Christian et al. [41. With this method, the emission of soot can be expressed as a function of the footprint which leaves the exhaust gases when passing through a filter.

Soot in oil is a parameter that needs more work to be measured [42. Traditionally, it was necessary to perform long time tests with the engine running in order to accumulate soot in the oil. Then, an engine oil sample is taken to be analysed in the laboratory. Commonly, the amount of soot is expressed in percentage by weight, hence, the most extended experimental technique for such quantification is the Thermal Gravimetric Analysis (TGA) 43, 44. TGA employs an oven that applies heat to the engine oil sample to modify its mass along the test analysis. The mass change is registered, providing information about the quantity of soot. 


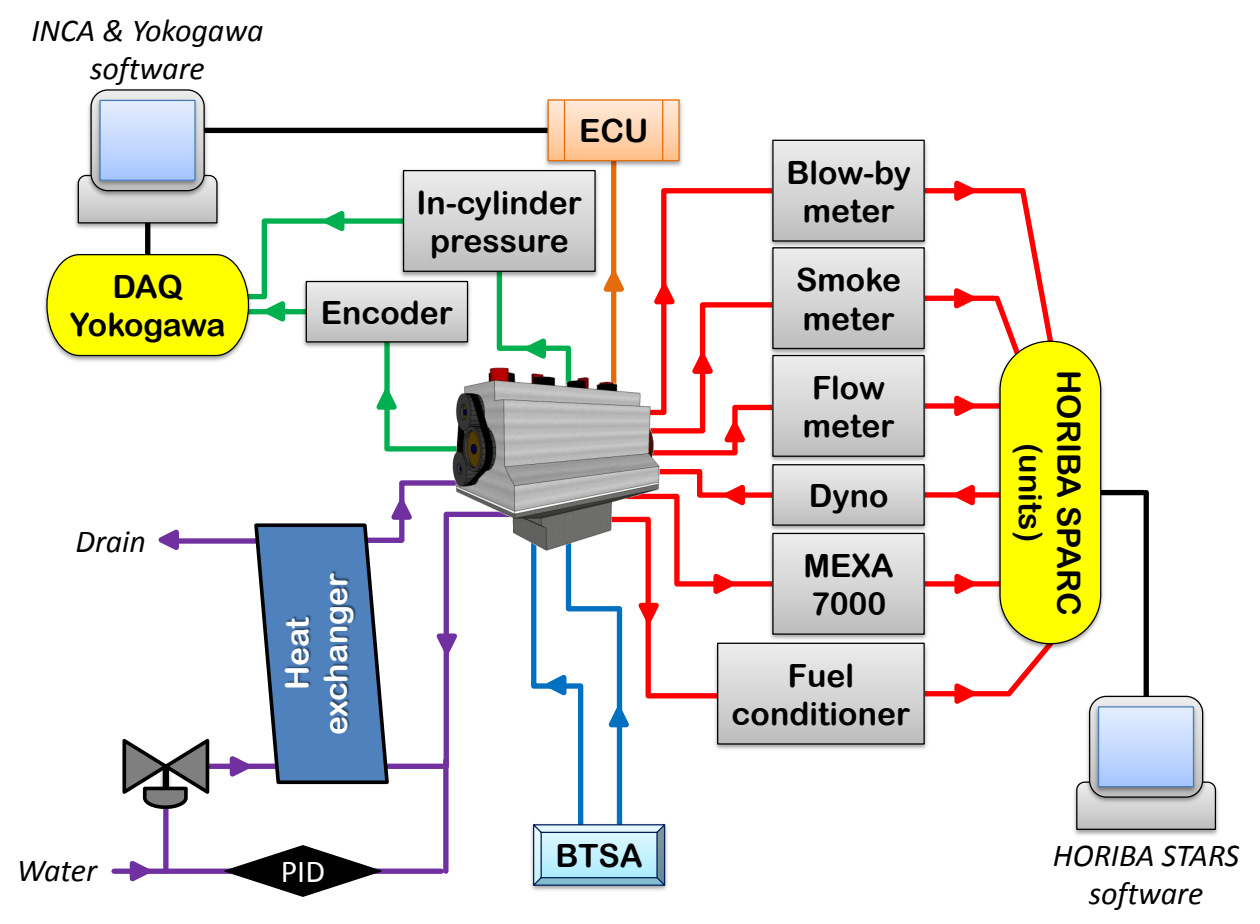

Figure 1: Engine test bench scheme.

The method is extremely precise, but it requires a long time to obtain the information. Another technique of interest is the Fourier-Transform Infrared spectroscopy (FTIR). The FTIR uses Infrared Radiation (IR) to excite the organic molecules of the sample to obtain the spectrum of the excitation. With the spectrum data, the components/contaminants (i.e. water, glycol, etc.) that are present in the sample and other relevant parameters of the oil (i.e. oxidation, nitration, sulfation, etc.) can be obtained [45. This technique needs short periods of time for being applied and it is also repeatable, however it does not always offer good accuracy.

The ideal measurement system to solve the problem faced on this study would be one capable of measuring with the TGA precision but with the speed of the FTIR. For this reason, a commercial device called Bench Top Soot Analyser (BTSA) of the Analytical Engineering Inc. (AEI) was chosen.

The BTSA [46] allows reading of soot-in-oil in real time while the engine is running. This device gives the soot concentration (by weight) in run-time and with great precision (0.0001\% approx.).

The measurement device utilizes a light source, which emits wavelengths from far infrared (>20 micron) to visible region ( 0.5 micron). Light and particle interactions preclude the transmission of certain wavelengths through the engine oil. The direct measurement of the intensity of this light can be correlated with the concentration of soot in the oil. This procedure is done by the BTSA using its own hydraulic system equipped with an external pump. The pump extracts the oil from the engine crankcase and returns it after the measuring procedure as is shown in Figure 2.

\subsection{Engine oil-fuel dilution measurements}

The fuel is the other element that affects the behaviour of the engine oil and it can be detected in the exhaust — with the presence of unburned hydrocarbons (HC) - and in the engine oil as well. In this case, the $\mathrm{HC}$ at the exhaust were measured with a state-of-the-art exhaust gas analyser, being this the simpler and the most accurate system to quantify the presence of $\mathrm{HC}$ in the exhaust smoke. 


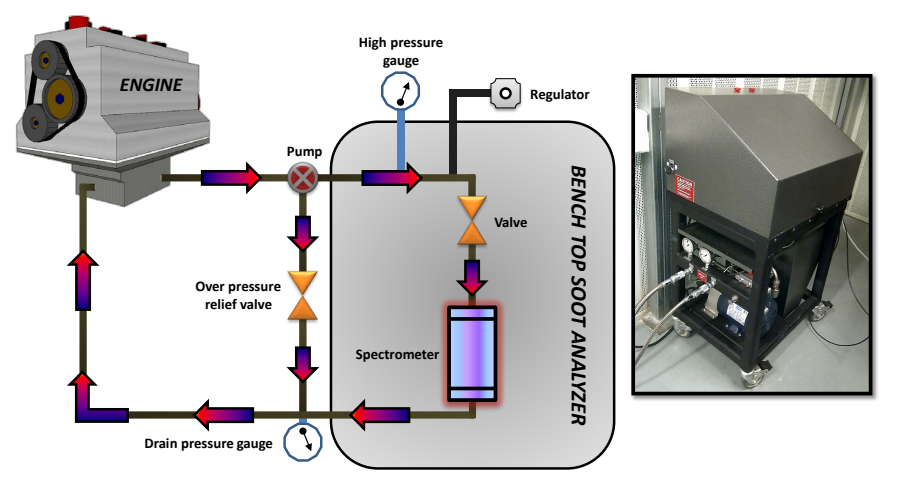

Figure 2: Schematic of the BTSA

However, the quantification of this element in the engine oil is more complex. Nonetheless, it is possible to obtain the concentration of fuel diluted in the oil by several techniques: Gas Chromatography (GC) [47, 48, FTIR and finally, it can be estimated using an indirect measurement: the kinematic viscosity (KV). The GC is an accurate technique to obtain the fuel concentration but it needs a specific equipment and a considerable time gap to obtain the results. The FTIR is faster than the GC technique, however, it is only valid for qualitative comparisons. The latter is based on the measurement of the kinematic viscosity of a given sample of engine oil. However, it is not possible to confirm that the variation of this parameter is only due to the fuel dilution since it depends on many other factors such as oil oxidation, soot concentration, oil shear, etc.

Despite their evident limitations, the presence of fuel in the oil was analysed using both FTIR and KV techniques since they may help to further understand certain trends observed in the soot-in-oil lectures.

\section{Numerical model description}

A numerical model of a single cylinder of the engine was implemented in the commercial code StarCD version 4.22 [49]. The mesh is a 1/9-sector mesh with periodic boundary conditions containing 131.360 cells at bottom dead center (BDC). This mesh size was obtained after a complete grid convergence study, which took into account the most relevant combustion parameters. The simulations were performed during the closed cycle [50, 51], this is from the closure of the intake valves to the opening of the exhaust ones (from $-113.2^{\circ}$ to $103^{\circ}$ with the TDC at $\left.0^{\circ}\right)$.

Turbulent flow properties were modelled by the RNG $k-\epsilon$ model [52], coupled with the wall-functions model proposed by Angelberger [53] to simulate the wall heat transfer. The time discretization was implicit, while the divergence terms used the second order Monotone Advection and Reconstruction Scheme (MARS) 49]. Pressure-velocity coupling was achieved by the Pressure Implicit with Splitting of Operators (PISO) method [54].

For combustion modelling, the ECFM-3z model from IFPEN [55 was employed. Other physical submodels were used to simulate the diesel injection process. The standard Droplet Discrete Model available in StarCD was used to calculate the diesel spray features. Spray atomization and break-up where simulated by means of the Huh-Gosman [56] and Reitz-Diwakar [57] models, whereas diesel fuel physical properties were given by the DF1 fuel surrogate [58. 
Concerning pollutants, $\mathrm{NO}_{\mathrm{x}}$ were approximated by the extended Zeldovich (thermal) mechanism, where source terms were acquired from a flamelet library [59]. Soot formation and oxidation, being of capital importance to this study, were calculated from a two-step Hiroyasu-like model [60. Lastly, a thermophoretic soot deposition model [61, 62 was implemented in the code to estimate the amount of soot mixed in the engine oil.

\section{Methodology}

Due to the complexity of the measuring techniques described above, accuracy was the most difficult aspect to assure the reliability of the conclusions reached. Although part of this inaccuracy comes from the measuring technique itself, a significant share also comes from the experimental methodology. Therefore, the use of accurate measurement devices is just as important as the methodology used to obtain the results. The section below describes the two methodologies used in this research.

The first step consisted of an extensive experimental campaign to characterize the soot content in both: the engine oil and the exhaust gases. This first characterisation not only allowed a first approximation to relieve the amount of soot particles in the engine oil but also permitted to recognize which are the most critical conditions within the whole operation map. The grid of steady operating conditions — defined by the engine speed and break mean effective pressure (BMEP) - shown in Fig. 3 were run in the engine. As can be seen in this figure, two different modes of combustion were considered: one associated with the regular engine operation, called conventional combustion, and other related to DPF regeneration. Therefore, ten different conditions (identified by circles) were chosen for conventional combustion to cover the whole engine operation map whereas four characteristic DPF regeneration conditions (squares) were also selected for comparison. Further details about these operating conditions are presented in Table 2 for reference.

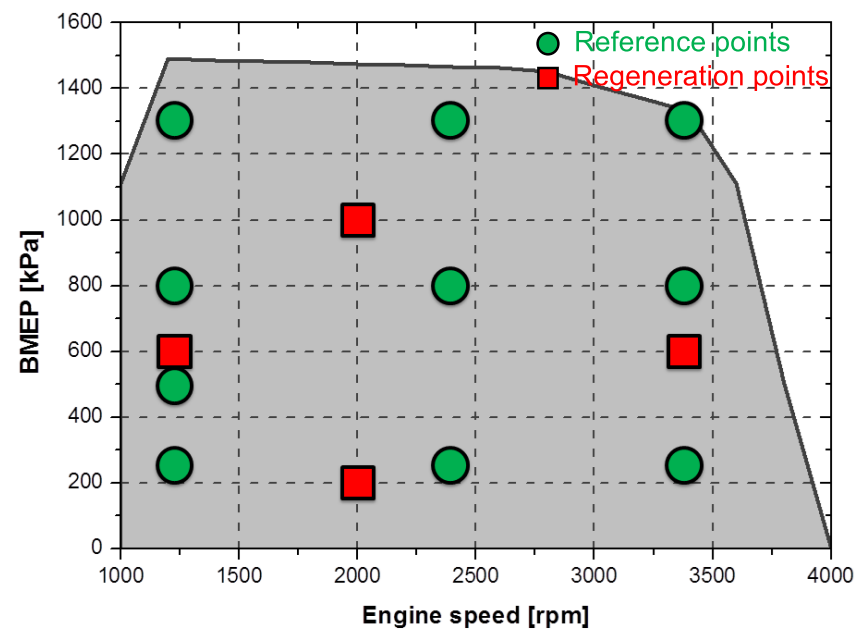

Figure 3: Engine operating points chosen for the analysis.

After selecting the reference engine operation conditions, a measurement of soot in both engine oil and exhaust gases was performed, obtaining thus the total soot generated during combustion considering both pathways. 
Table 2: Main running settings of the operation points considered for the soot-in-oil analysis.

\begin{tabular}{|c|c|c|c|c|c|c|c|c|c|c|c|c|c|c|}
\hline ID & $1200 @ 2.5$ & $1200 @ 5$ & $1200 @ 8$ & $1200 @ 13$ & $2400 @ 2.5$ & $2400 @ 8$ & $2400 @ 13$ & $3400 @ 2.5$ & $3400 @ 8$ & $3400 @ 13$ & $1200 @ 6$ & $2000 @ 2$ & $2000 @ 10$ & $3400 @ 6$ \\
\hline Engine speed [rpm] & 1200 & 1200 & 1200 & 1200 & 2400 & 2400 & 2400 & 3400 & 3400 & 3400 & 1200 & 2000 & 2000 & 3400 \\
\hline BMEP $[\mathrm{kPa}]$ & 250 & 500 & 800 & 1300 & 250 & 800 & 1300 & 250 & 800 & 1300 & 600 & 200 & 1000 & 600 \\
\hline EGR [\%] & 31.0 & 18.0 & 13.1 & 0.2 & 37.4 & 21.8 & 11.7 & 16.0 & 17.1 & 17.6 & 0.3 & 0.2 & 0.1 & 0.2 \\
\hline Combustion mode $[-]$ & $\mathrm{C}$ & $\mathrm{C}$ & $\mathrm{C}$ & $\mathrm{C}$ & $\mathrm{C}$ & $\mathrm{C}$ & $\mathrm{C}$ & $\mathrm{C}$ & $\mathrm{C}$ & $\mathrm{C}$ & $\mathrm{R}$ & $\mathrm{R}$ & $\mathrm{R}$ & $\mathrm{R}$ \\
\hline Injection pressure [bar] & 536 & 672 & 733 & 750 & 1042 & 1397 & 1268 & 1008 & 1574 & 1799 & 693 & 456 & 794 & 1073 \\
\hline SoI $_{\text {pilot }_{1}}[\mathrm{CAD}]$ & -16.0 & -19.8 & -25.2 & - & -27.4 & - & - & - & - & - & - & - & - & \\
\hline SoI $_{\text {pilot }_{2}}[\mathrm{CAD}]$ & -1.6 & -2.0 & -8.2 & -20.4 & -6.8 & -23.6 & -11.8 & -17.2 & -20.6 & -10.8 & -19.6 & -13.0 & -25.2 & -21.4 \\
\hline SoI main $[\mathrm{CAD}]$ & 7.2 & 7.2 & 5.0 & -3.2 & 3.6 & 4.4 & 1.0 & 1.2 & -2.4 & -10.8 & 7.4 & 5.6 & 1.4 & -4.8 \\
\hline SoI I ost $\left._{[\mathrm{CAD}}\right]$ & - & & - & - & - & - & - & - & - & 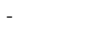 & 54.6 & 39.9 & 48.2 & 52.0 \\
\hline $\mathrm{MoI}_{\text {pilot }_{1}}[\mathrm{mg} / \mathrm{str}]$ & 1.5 & 2.3 & 2.8 & - & 3.0 & - & - & - & - & - & - & - & - & 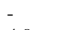 \\
\hline MoI $_{\text {pilot }}[\mathrm{mg} / \mathrm{str}]$ & 0.7 & 1.0 & 1.3 & 1.4 & 2.3 & 1.7 & 1.7 & 2.6 & 1.7 & 2.7 & 2.5 & 5.1 & 2.9 & 4.9 \\
\hline MoI $I_{\text {main }}[\mathrm{mg} / \mathrm{str}]$ & 11.6 & 22.5 & 34.5 & 57.7 & 11.5 & 39.3 & 61.4 & 18.2 & 43.7 & 61.2 & 26.0 & 10.7 & 44.6 & 26.4 \\
\hline $\operatorname{MoI}_{\text {post }}[\mathrm{mg} / \mathrm{str}]$ & 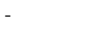 & 年 & - & - & - & - & - & - & - & - & 9.4 & 7.6 & 6.8 & 4.4 \\
\hline
\end{tabular}

The BTSA device requires an specific experimental procedure to obtain accurate measurements. First, the engine remains in the selected operating condition for 15 minutes in order to stabilize all operating parameters. After that, the BTSA analysis continues until one hour is completed. This period is required in order to achieve an optimal precision according to AEI recommendations [46]. In the 45 remaining minutes, the BTSA gets the instant value of soot-in-oil concentration every 6 seconds. In parallel, engine outputs were registered every 15 minutes. The four samples of the engine operating parameters registered during the analysis were averaged post test.

Regarding the measurement of the exhaust emissions, the opacimeter described in section 2 was synchronized with the measurements of the engine parameters and also with the BTSA to obtain the soot generation rate. Thanks to this analysis was possible to quantify the amount of soot that remained in the engine oil and which one is emitted directly to the atmosphere.

Simultaneously, analyses of fuel dilution in oil (using both KV measurements and FTIR) and exhaust tailpipe $\mathrm{HC}$ emissions were carried out to determine the proportion of fuel remaining in the engine oil and in the exhaust.

After this study, five parametric studies were performed. The reference points for these studies were selected after the analysis of the aforementioned reference conditions, thereby the effect of some engine operation settings on the most interesting points can be examined in detail. The parameters considered were: EGR, injection pressure (IP), fuel injection timing — or start of injection (SoI) - and fuel mass injected (MoI). The measurement procedure was the same as in the previous study.

In the second step of this investigation, the dynamics and spatial mechanisms of soot-in-oil deposition were numerically simulated to complement the experimental studies. In this case, 2 operating points were simulated: conventional combustion at $3400 \mathrm{rpm}$ and $1300 \mathrm{kPa}$ (3400@13) and DPF regeneration mode at $2000 \mathrm{rpm}$ and $200 \mathrm{kPa}(2000 @ 2)$. The numerical results were compared against the experiments and then, advantage was taken from the spatial information available to further characterise the soot-in-oil mechanisms.

\section{Results and discussion}

The section below describes the results obtained after the application of the aforementioned methodology. Results regarding the reference and DPF regeneration conditions are introduced first. Then, the results of the different parametric studies are presented and discussed. Finally, the CFD model is validated over several operating conditions and the numerical results are also shown.

\subsection{Reference conditions}

Figure 4 shows the soot measurement results of all reference tests. In this figure, the amount of soot registered at oil and tailpipe is plotted for each operating condition. Although a correlation between the content of soot in the oil and in the exhaust may be expected, this relationship is not observed in the figure. However, some particular points can be highlighted due to the peculiarity of the observed trends. Three points stand out for their high values of soot-in-oil: 2400@13,3400@8 and 3400@13, all of them being focused 
on the top-right region of the map, characterized by high load and high speed conditions. Nonetheless, the ratio between the soot value in the oil and in the exhaust is very different among these points. While the amount of $\mathrm{SiO}$ is almost $38 \%$ of the exhaust emission for point $2400 @ 13$, it does not exceed $21 \%$ and $6 \%$ for points 3400@8 and 3400@13, respectively.

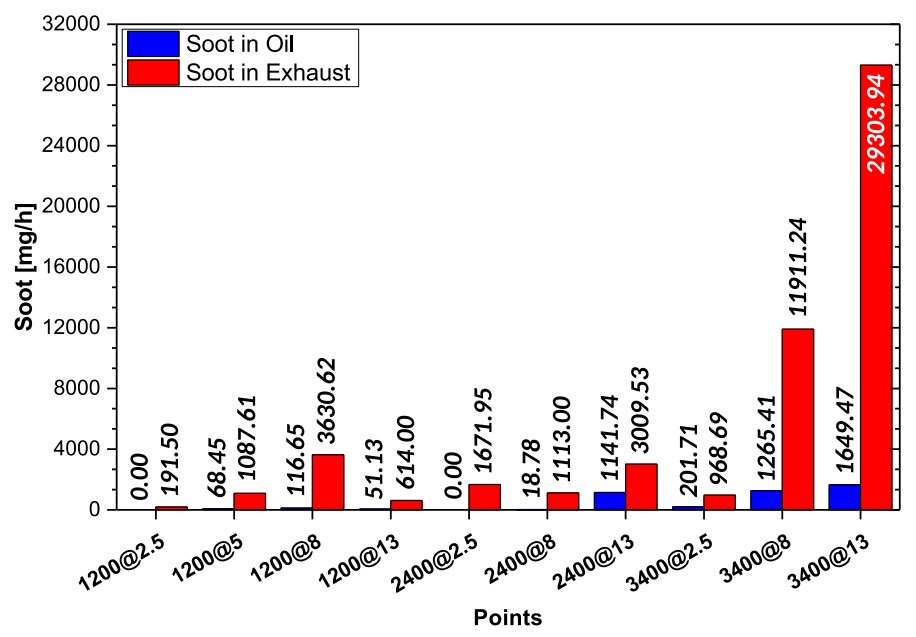

Figure 4: Soot in oil and exhaust content for all conventional combustion operating conditions.

In contrast to these conditions, point 1200@2.5 - with low load and low engine speed - shows the lowest soot level in the exhaust. Moreover, the amount of the soot in the engine oil represents $10 \%$ of this registered value.

Similarly to what is done for the conventional combustion conditions, the soot-in-oil and exhaust soot values are shown in Fig. 5 for all DPF regeneration points. Comparing these results with those obtained for the reference conditions, there are some interesting aspects that contradict what might be expected. Due to the excessively delayed post injections, the local equivalence ratio at the reaction regions tend to increase, while the incomplete combustion during the expansion stroke favours the generation of soot particles. By contrast, it is not observed that soot values, whether in the exhaust or in the oil, are systematically higher than in the reference conditions. In fact, they are in the order of most of the reference points located at the central area of Fig. 4 and even being widely surpassed by those with high load/speed conditions.

Nevertheless, a certain variety still appears in the distribution of soot particles. For instance, the points 1200@6 and 2000@10 are characterised by a low presence of soot in exhaust in spite of showing a considerable soot-in-oil content. In addition, the other two points (2000@2 and 3400@6) contrast with these previous ones since they exhibit nearly zero levels of $\mathrm{SiO}$ with low and high levels in the exhaust, respectively.

In view of these trends, specially those related to the soot levels between reference and DPF regeneration modes, further analysis is needed to completely characterise the problem and to understand all physical mechanisms involved. Therefore, several parametric studies were performed and presented in the section below to identify which operating strategies may help to decrease soot-in-oil levels while additional analysis were carried out to recognise possible effects that could affect soot measurements (e.g. fuel dilution).

\subsection{Validation of BTSA measurements}

Oil dilution caused by combustion products may cause interference in the soot-in-oil predictions. This phenomenon may be particularly evident during the DPF regeneration where the post injection fails to completely burn and subsequently, a meaningful amount of unburned fuel collides with the oil-impregnated cylinder walls. These unburned hydrocarbons produce alterations in the internal structure of the oil modifying its physical properties. 


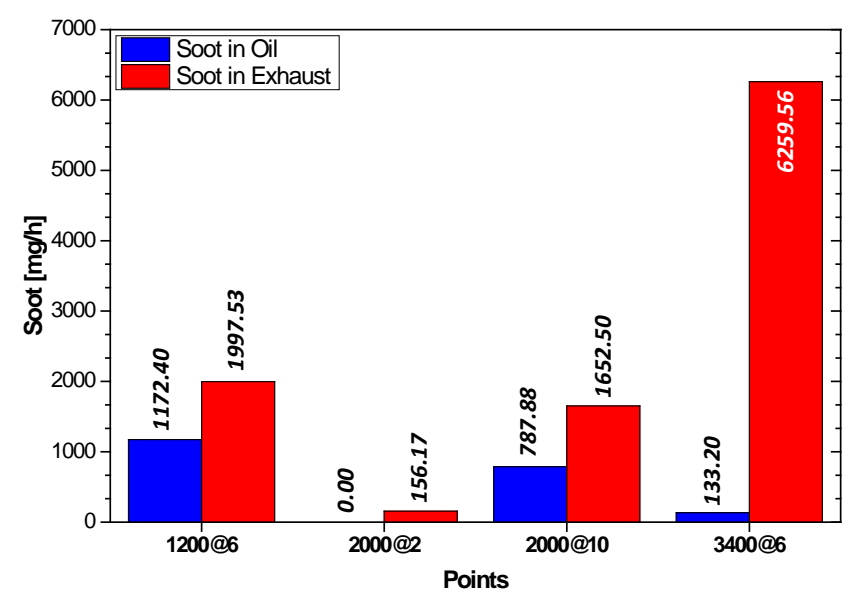

Figure 5: Soot in oil and exhaust content for all DPF regeneration operating conditions.

In order to validate the BTSA measurements, we resorted to other techniques that in spite of being less suitable for the type of analysis to be performed in this investigation, may complement the results and the understanding of the most extreme trends. Specifically, the KV and FTIR analyses were used to estimate both fuel dilution and soot-in-oil content variations.

The KV analysis and FTIR methodology consisted of collecting small engine oil samples at the beginning and the end of each of 1-hour test. Then both samples were analysed a post test to determine the variation of the engine oil viscosity, soot content and fuel dilution. In this way, the $\mathrm{KV}$ technique allows to discern the presence of $\mathrm{SiO}$ (which increases KV) and/or the possible dilution by fuel (which reduces KV). Thereby, a negative variation means a viscosity reduction due to the fuel dilution whereas a positive one signifies a viscosity increase due to the presence of soot-in-oil. Following a different approach (described in section 2.3) but using the same procedure for the oil samples collection, FTIR allowed to quantify the agents diluted in the oil in relative terms.

Results from both analyses are summarized in Fig. 6, in which the KV variation is plotted for all reference tests considered. The relative variation of soot and fuel estimated by the FTIR method are also shown for the most relevant points. Moreover, this figure includes the variation in the soot-in-oil levels registered by the BTSA device as well as both soot and HC values measured at the exhaust tailpipe by the exhaust analyser.

In this figure, an interval between $\pm 1.5 \%$ of $\mathrm{KV}$ variation is highlighted. Within this, it is not possible to know that the KV variation is due purely to pure the effect of dilution since the error of the measurement method is of the same order. Four operating points can be identified outside this confidence interval where the observed variation is mainly due to soot-in-oil content and/or fuel dilution.

The first point corresponds with a low speed-load test (1200@2.5). The increased KV should indicate the presence of soot-in-oil. However, soot levels measured by the BTSA device are almost zero. This inconsistency can be explained by the FTIR measurements, the negative values of both $\Delta$ soot and $\Delta$ fuel indicate that coherency of this measurement is questionable. Therefore, this point was not considered for further analyses.

Next following points (2400@13 and 3400@13) also show an increase in the oil KV but, in this case, both soot-in-oil measurements support this trend.

Last point (2000@2) shows an oil KV reduction, explained by the presence of fuel in the oil detected by the FTIR technique. It is also interesting to note the direct relationship between HC levels registered at the oil and exhaust. Regarding the soot, the values estimated by FTIR show that despite detecting a certain amount, this is not relevant if it is compared with the other points. 


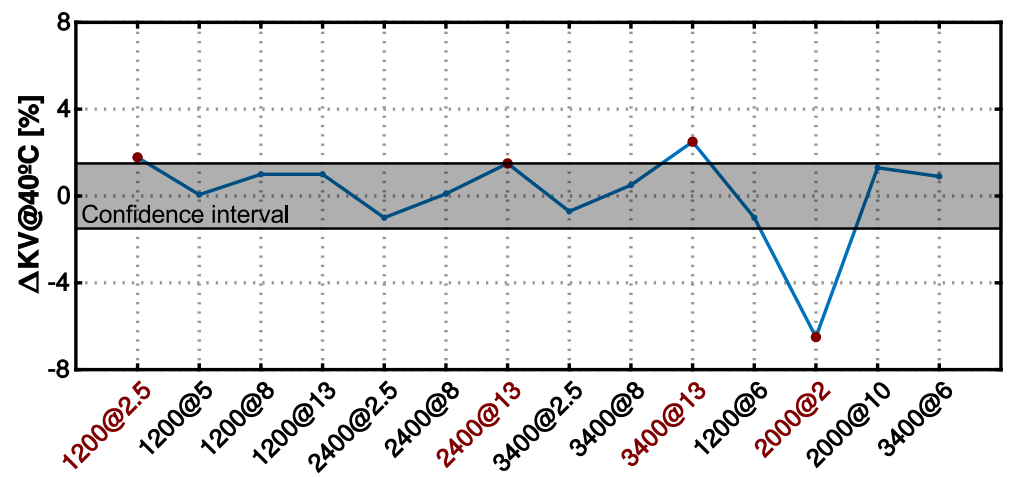

\begin{tabular}{clllll}
\hline ID & $\begin{array}{l}\Delta \mathbf{K V} @ \mathbf{4 0}{ }^{\circ} \mathbf{C} \\
{[\%]}\end{array}$ & $\begin{array}{l}\Delta \text { Soot-in-oil (BTSA) } \\
{[\%]}\end{array}$ & $\begin{array}{l}\Delta \text { Soot-in-oil (FTIR) } \\
{[\%]}\end{array}$ & $\begin{array}{l}\Delta \text { Fuel in oil (FTIR) } \\
{[\%]}\end{array}$ & $\begin{array}{l}\text { HC in exhaust } \\
{[\mathrm{g} / \mathrm{h}]}\end{array}$ \\
\hline $1200 @ 2.5$ & 1.78 & -0.33 & -1.67 & -13.99 & 5.019 \\
$2400 @ 13$ & 1.50 & 4.64 & 11.38 & 2.05 & 9.403 \\
$3400 @ 13$ & 2.50 & 7.08 & 34.18 & 6.91 & 12.498 \\
$2000 @ 2$ & -6.50 & -0.75 & 2.97 & 15.07 & 454.876 \\
\hline
\end{tabular}

Figure 6: Variation of kinematic viscosity at $40^{\circ} \mathrm{C}$, soot-in-oil content, fuel dilution and $\mathrm{HC}$ in the exhaust for reference tests.

Analysing the data presented in this section, has shown the consistency among all measurement techniques used in this investigation, thus validating the BTSA methodology. In addition, the combination of these techniques also contributes to enhance the comprehension of the most peculiar trends.

\subsection{Parametric studies}

After the analysis of the reference and DPF regeneration conditions, A series of parametric studies were carried out considering the most interesting operation conditions and several modifications of EGR, injection pressure, injection timings and injected fuel mass. Table 3 show the main settings used for all the studies presented below. Note that the selected points (including both reference and DPF regeneration modes) were utilized as baseline cases for comparison.

\subsubsection{Influence of EGR}

The first study is based on analysing the effect of EGR since the presence of residual gases within the combustion chamber promotes the soot generation. The reference points 1200@13 and 3400@13 were chosen due to their extreme trends. On the one hand, point 1200@13 exhibit the lowest levels of soot at the exhaust and diluted in the engine oil (without becoming zero). On the other hand, point 3400@13 show the largest levels of soot registered at both locations.

According to Table 3, the amount of EGR was increased in both operating conditions. The EGR rate was extended from $0 \%$ to $8 \%$ for point $1200 @ 13$ and from $17.6 \%$ to $19.8 \%$ for point $3400 @ 13$. In both cases the new measured points were denoted as 1200@13_EGR and 3400@13_EGR.

Figure 7 shows the results of this study. The amount of soot particulates in the oil and exhaust is drawn following the same representation used in Fig. 4. As expected, the soot content increases with the EGR rate, specially the one registered at the exhaust that can even be multiplied by 12 in point $1200 @ 13$ (it has the larger increase of EGR).

\subsubsection{Influence of the injection pressure}

For the analysis of the injection pressure effect, the same reference points considered for the previous study were utilized. In this case the baseline injection pressure was decreased 200 bar in both cases, going from 750 bar to 550 bar in point 1200@13_IP and from 1800 bar to 1600 in point 3400@13_IP. Results plotted in Fig. 8 show the results of soot measurements. A slight reduction of soot-in-oil levels is observed in both 
Table 3: Engine settings for all parametric studies.

\begin{tabular}{|c|c|c|c|c|c|c|}
\hline Study & ID & EGR [-] & IP $[$ bar $]$ & SoI $_{\text {main }}[\mathrm{CAD}]$ & SoI $_{\text {post }}[\mathrm{CAD}]$ & MoI $_{\text {post }}[\mathrm{mg} / \mathrm{str}]$ \\
\hline \multirow{4}{*}{ EGR } & 1200@13 & 0.0 & 750 & -3.1 & - & 59.0 \\
\hline & 1200@13_EGR & 8.0 & 752 & -3.2 & - & 59.0 \\
\hline & $3400 @ 13$ & 17.6 & 1800 & -10.8 & - & 60.4 \\
\hline & 3400@13_EGR & 19.8 & 1800 & -10.8 & - & 60.3 \\
\hline \multirow{4}{*}{ IP } & $1200 @ 13$ & 0.0 & 750 & -3.1 & - & 59.0 \\
\hline & 1200@13_IP & 0.0 & 550 & -3.2 & - & 59.8 \\
\hline & 3400@13 & 17.6 & 1800 & -10.8 & - & 60.4 \\
\hline & 3400@13_IP & 16.8 & 1600 & -10.8 & - & 60.2 \\
\hline \multirow{8}{*}{ SoI $_{\text {main }}$} & $1200 @ 13$ & 0.0 & 750 & -3.1 & - & 59.0 \\
\hline & 1200@13_SoI main & 0.0 & 752 & 0.8 & - & 59.0 \\
\hline & 3400@13 & 17.6 & 1800 & -10.8 & - & 60.4 \\
\hline & 3400@13_SoI main & 15.8 & 1800 & -6.8 & - & 60.4 \\
\hline & $2000 @ 2$ & 0.0 & 456 & 5.6 & 39.9 & 23.3 \\
\hline & $2000 @ 2 \_S_{\text {main }}$ & 0.0 & 440 & 9.4 & 39.8 & 22.7 \\
\hline & 2000@10 & 0.0 & 794 & 1.4 & 48.2 & 49.5 \\
\hline & 2000@10_SoI main & 0.0 & 789 & 4.4 & 48.2 & 49.4 \\
\hline \multirow{6}{*}{ SoI $_{\text {post }}$} & $1200 @ 6$ & 0.0 & 693 & 7.4 & 54.6 & 37.7 \\
\hline & 1200@6_SoI ${ }_{\text {post }}$ & 0.0 & 693 & 7.4 & 50.6 & 37.7 \\
\hline & $3400 @ 6$ & 0.0 & 1073 & -4.8 & 52.0 & 36.2 \\
\hline & 3400@6_SoI ${ }_{\text {post }}$ & 0.0 & 1075 & -4.8 & 47.8 & 36.3 \\
\hline & 2000@2 & 0.0 & 456 & 5.6 & 39.9 & 23.3 \\
\hline & 2000@2_SoI ${ }_{\text {post }}$ & 0.0 & 456 & 5.6 & 35.8 & 23.4 \\
\hline \multirow{6}{*}{$\mathrm{MoI}_{\text {post }}$} & $1200 @ 6$ & 0.0 & 693 & 7.4 & 54.6 & 37.7 \\
\hline & 1200@6_Fuel & 0.0 & 691 & 7.2 & 54.6 & 35.6 \\
\hline & $3400 @ 6$ & 0.0 & 1073 & -4.8 & 52.0 & 36.2 \\
\hline & 3400@6_Fuel & 0.0 & 1075 & -4.8 & 52.2 & 34.1 \\
\hline & $2000 @ 2$ & 0.0 & 456 & 5.6 & 39.9 & 23.3 \\
\hline & 2000@2_Fuel & 0.0 & 456 & 5.6 & - & 16.2 \\
\hline
\end{tabular}

operating conditions. Nonetheless, this reduction is much larger in point 1200@13_IP (75\% approx.) than in point 3400@13_IP (25\% approx.). It seems that the lower momentum flux achieved by the spray due to the lower injection pressure lead to less penetration and, therefore, it minimizes the likelihood of soot reaching oil film on the cylinder walls.

Regarding exhaust soot levels, results are less consistent with what is a priori expected. Lower injection pressures tend to generate higher levels of soot due to an inefficient fuel burning. The bigger fuel droplets reduce the total contact surface between the oxygen and fuel, hindering the fuel oxidation while enhancing soot particles nucleation. This effect can be clearly observed in point 1200@13_IP, where exhaust soot quantity significantly increases whereas the amount of soot-in-oil decreases though. However, this effect is not observed when the engine speed is increased (point 3400@13_IP). In this case, soot emissions are less sensitive to injection pressure since the values of soot particles at the exhaust are scarcely altered for the same variation of IP.

\subsubsection{Effect of the fuel injection timing}

The fuel injection timing may also play a relevant role in the soot generation and its subsequent mixing in the engine oil. This study focuses on analysing the influence of main and post injection timings. First, the main injection timing was delayed $4 \mathrm{CAD}$ in two conventional combustion points (1200@13_SoI $\mathrm{I}_{\text {main }}$ and 3400@13_SoI $\left.I_{\text {main }}\right)$ and two in DPF regeneration mode (2000@2_SoI main and 2000@10_SoI $\left.I_{\text {main }}\right)$. Then, the post injection timing was also modified in three of the DPF regeneration points $\left(1200 @ 6\right.$ SoI $_{\text {post }}, 2000 @ 2$ _SoI $\mathrm{I}_{\text {post }}$ and 1200@6_SoI $\left.{ }_{\text {post }}\right)$. 

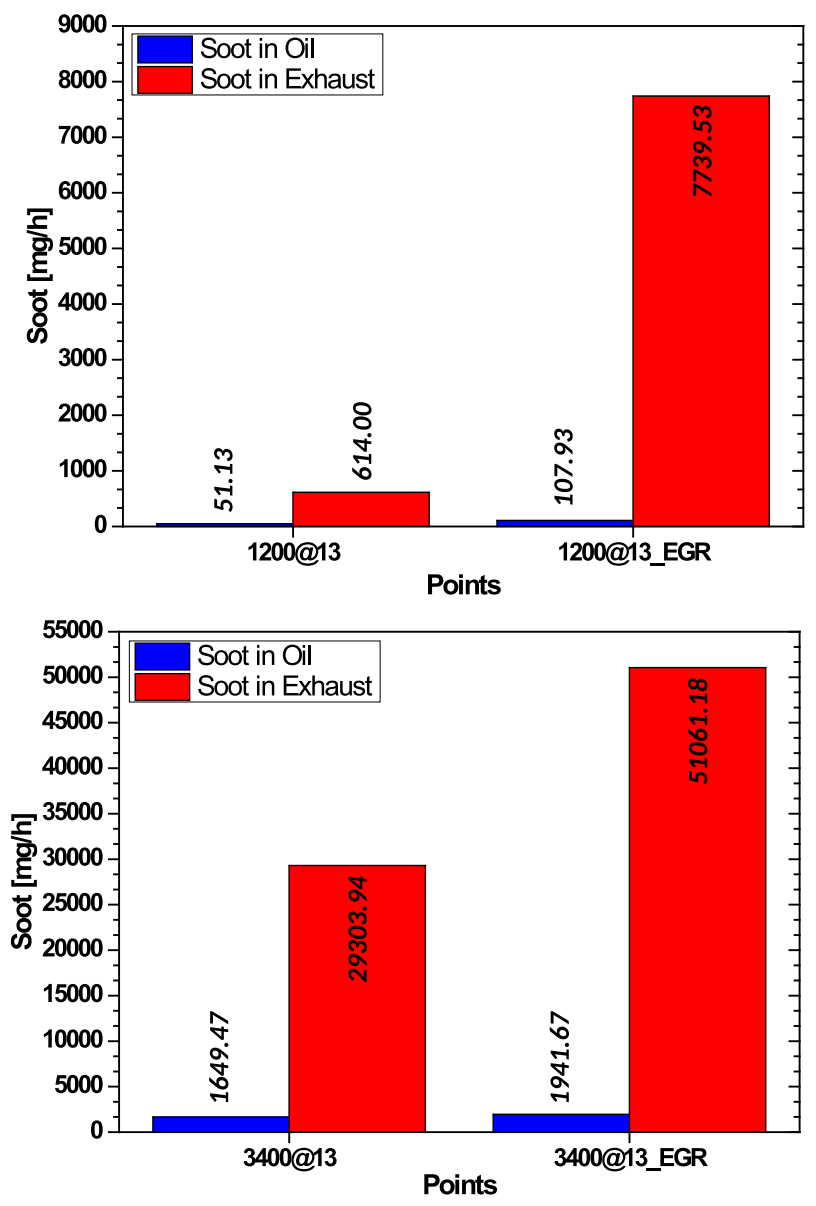

Figure 7: Impact of EGR on the soot content.

Inspecting the measurements of the two conventional combustion points drawn in Fig. 9 it is clearly seen that both operation conditions experience similar trends in terms of $\mathrm{SiO}$ values. In both cases the amount of soot in the oil decreases to the point of reaching null values in point 1200@13_SoI main. It seems that despite increasing the oil film exposed when delaying the main injection and thus the combustion, soot particles are generated far from the cylinder walls and most of the soot is evacuated from the combustion chamber before diluting in the oil.

Continuing this comparison, delaying the main injection towards the expansion stroke seems to be an appropriate strategy to reduce soot exhaust emissions at high engine speeds but is not effective under low engine speed conditions. In this latter situation, the lower temperature dissipation due to the decreased engine speed favour the soot generation.

Regarding the results obtained when the main injection timing in a DPF regeneration cycle is modified +4 CAD, it is possible to observe though the Fig. 10 that trends are very similar to those already reported by the reference points. Both soot concentrations, in the engine oil and the exhaust, are reduced when delaying the main injection at high load conditions (2000@10_SoI main). Moreover, soot-in-oil levels are zero at low load conditions $\left(2000 @ 2\right.$ SoI $_{\text {main }}$ ) whereas exhaust emissions do not significantly change. In general, results confirm that delaying the main injection may help to control the amount of soot particulates in the engine oil to prevent derived engine failures. 

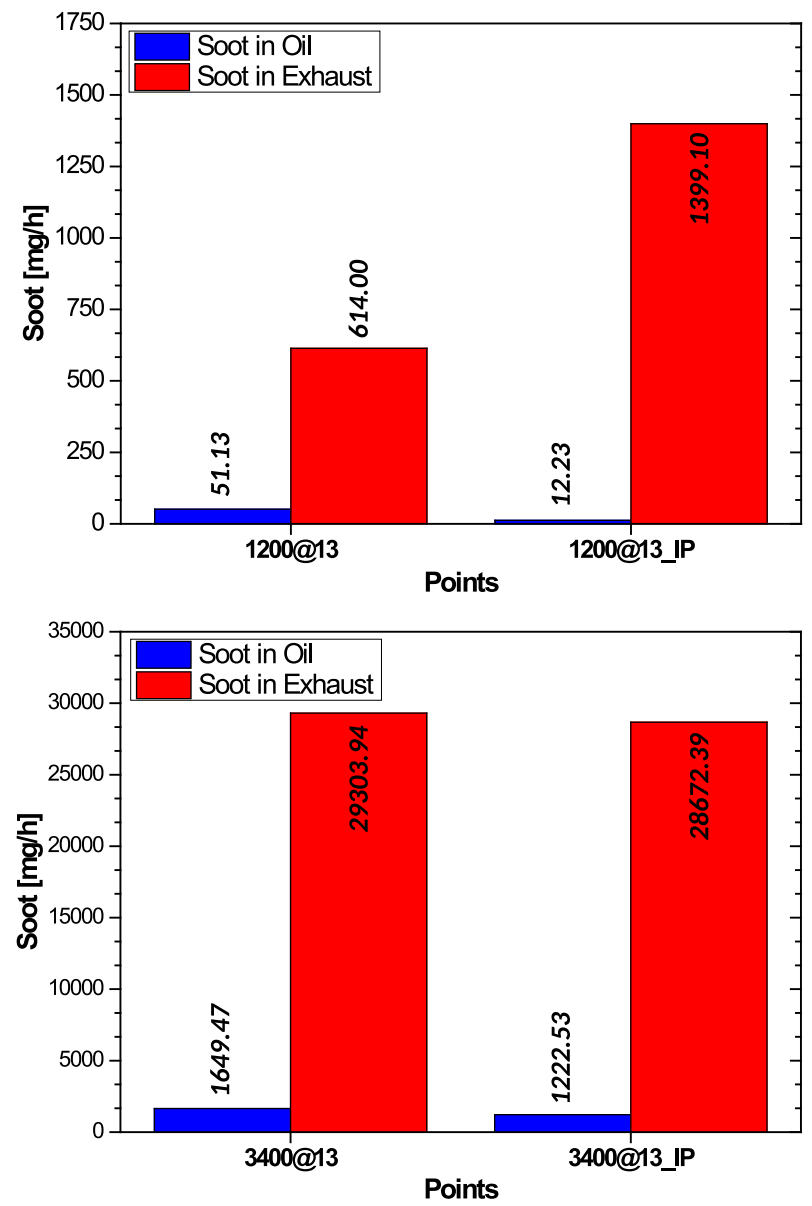

Figure 8: Influence of injection pressure on the soot content.

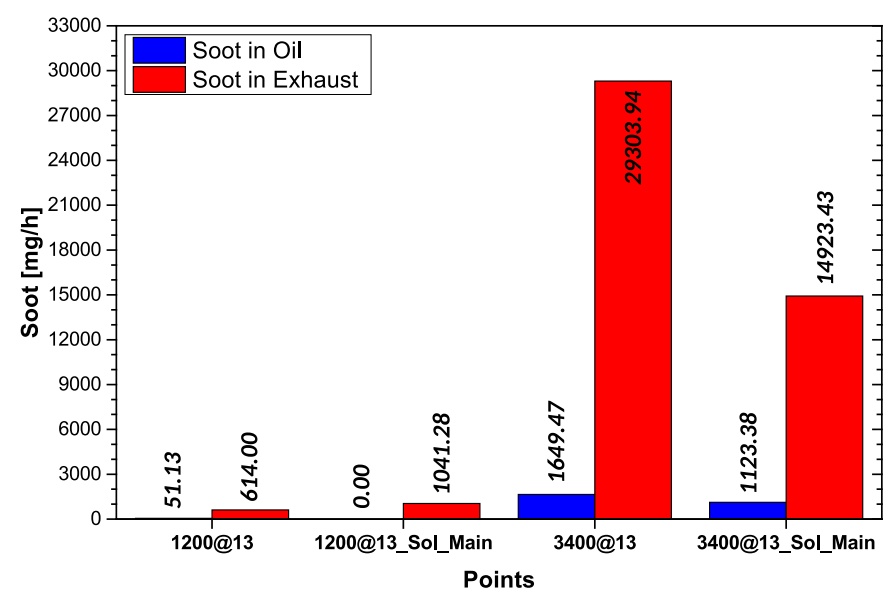

Figure 9: The effect of injection delay (main) on the soot content for conventional combustion mode. 


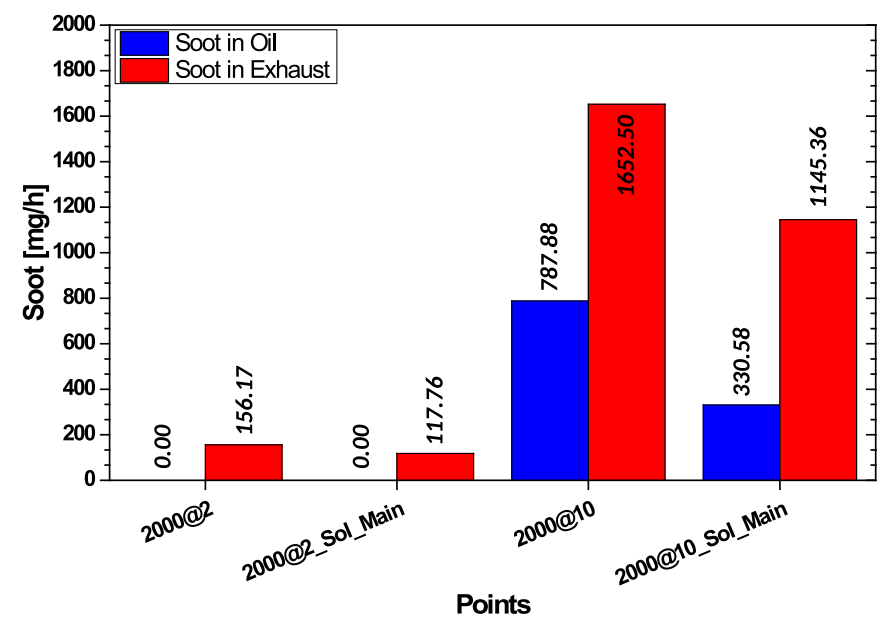

Figure 10: The effect of injection delay (main) on the soot content for DPF regeneration modes.

In order to complete the analysis, an additional study related to the injection timing effect was performed. In this case, the SoI of the post injection was modified (-4 CAD) in the DPF regeneration points 1200@6_SoI post $_{\text {, }}$

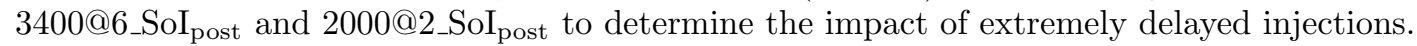

Figure 11 show the soot content measured at these new test conditions. It can be seen in the graphs that the soot-in-oil content increases when the post injection is advanced at low engine speeds while soot emissions remain almost constant. However, none of both parameters are excessively altered at higher engine speeds. This behaviour seems to indicate that the $\mathrm{SiO}$ dilution mechanisms are different as the engine speed changes.

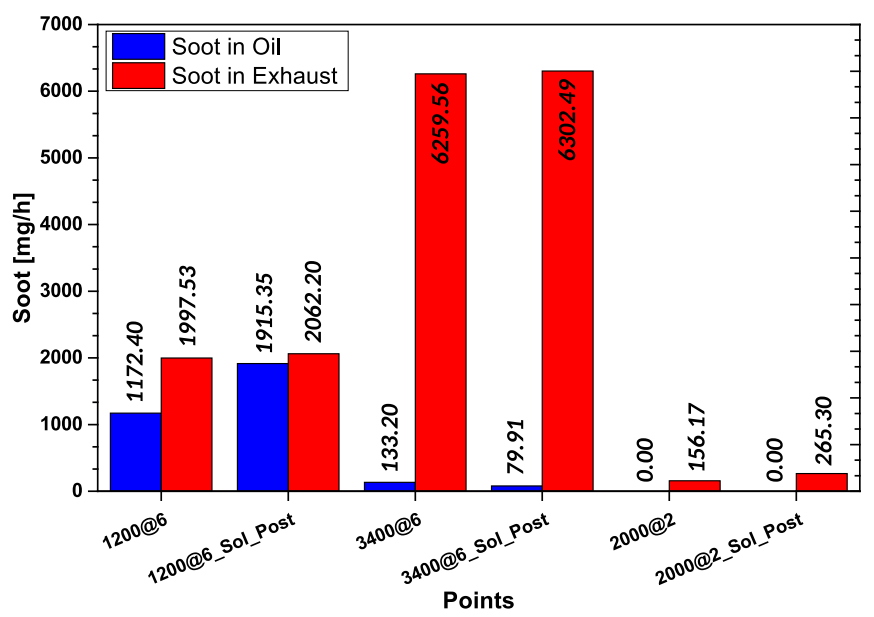

Figure 11: The effect of injection delay (post) on the soot content for DPF regeneration modes.

\subsubsection{Effect of the injected fuel mass}

The last parametric study is focused on analysing the influence of the injected fuel mass during the post injection event. For this study, the amount of fuel injected during the post injection was reduced according to Table 3 in this three DPF regeneration points: 1200@6,3400@6 and 2000@2. The idea is to compare the effect of $\mathrm{SoI}_{\text {post }}$ (already reported in the previous section) and $\mathrm{MoI}_{\text {post }}$ directly. 


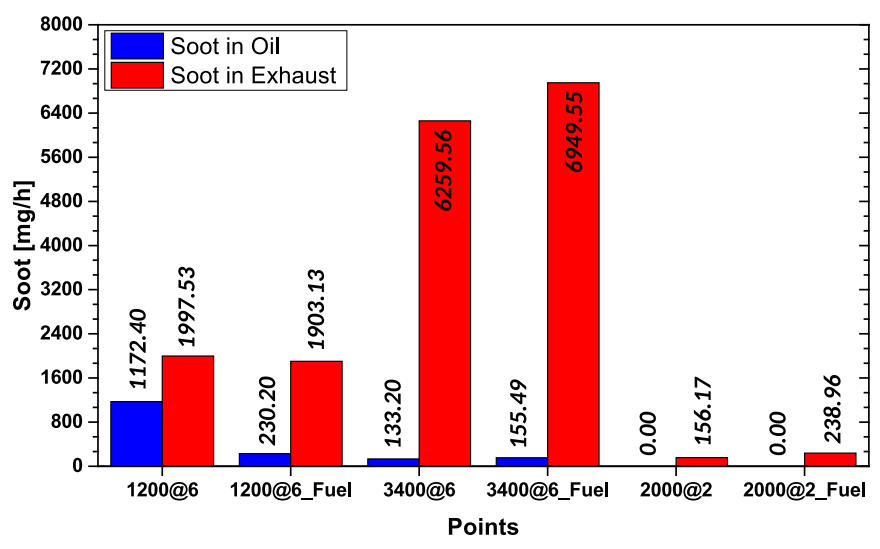

Figure 12: The effect of injected fuel mass (post) on the soot content for DPF regeneration modes.

Examination of the results drawn in Fig 12 shows again that there are some differences among low and medium-high engine speeds. In the former conditions (point 1200@6), the SiO content decreases significantly whilst emissions levels are scarcely altered when the injected fuel is decreased in the post injection event. In contrast to this, neither parameters exhibit any remarkable difference at $3400 \mathrm{rpm}$ and $2000 \mathrm{rpm}$, where the post injection was removed.

After the results examination, some questions arise regarding the validity of the measurements offered by the BTSA device. In particular, trends observed in the studies focused on the post injection timing and injected mass when operating under DPF regeneration mode, are questionable since they do not follow a coherent pattern. Moreover, point 2000@2 shows no sensitivity to the changes made in post injection settings; $\mathrm{SiO}$ levels are always zero regardless of the settings used.

In view of this an additional analysis, analogous to that carried out in section 5.2 , was performed to validate all measurements and to corroborate the conclusions obtained from them.

Thereby, the variation of the kinematic viscosity between the beginning and end of all tests performed in this section is plotted in Fig. 13 . Again, only four points are outside the confidence interval $( \pm 1.5 \%)$, that do not assure that the KV variation is only due to a possible dilution either in terms of soot or fuel. As happened with the reference point 2400@13, the increment of KV observed in point 3400@13_EGR can be explained by the increased soot-in oil amount detected by BTSA and also by FTIR techniques. Since the levels of $\mathrm{HC}$ in the oil and at the exhaust do not show a significant increment, the fuel dilution can be considered small and this measurement can be considered fully valid.

In the other three points we can see the opposite situation, where the KV decreases due to the fuel dilution. Note that, as in the reference point 2000@2, the levels of HC registered by the exhaust analyser are considerable if they are compared with point 3400@13_EGR. Moreover, the fuel dilution measured by FTIR is also high, specially in points 2000@2_SoI main and 2000@2_SoI ${ }_{\text {post }}$.

In comparison with the reference point 2000@2, FTIR predicted values of soot-in-oil are significantly larger, evidencing a clear inconsistency with the BTSA measurements. It seems that excessive oil dilution disguise the real content of soot particles in the oil when using BTSA device. For this reason, these measurements should be considered with caution when drawing any conclusion.

\subsection{Analysis of numerical simulations}

In spite of the fact that the studies carried out have made it possible to analyse the effects of the main emissions-control strategies in the $\mathrm{SiO}$ content, the relationship between the soot generated during combustion and the quantity of it that mixes with the oil is not yet established. In the same way, the effect of fuel dilution has also not been established due to the characteristics of the BTSA measurement method. Hence, a further analysis is performed in the section below in order to try to clarify all these issues. The CFD model described in section 3 was used for this purpose. 


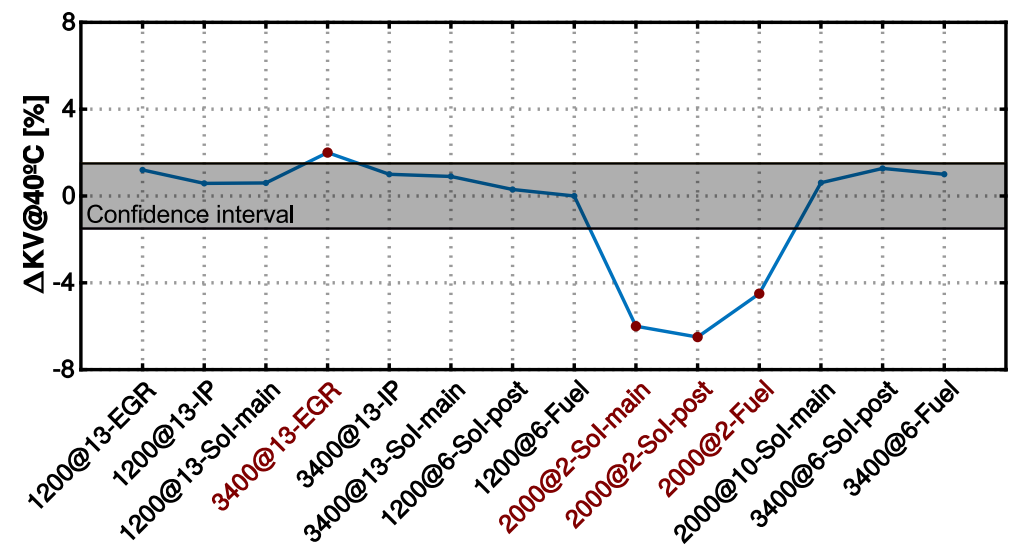

\begin{tabular}{clllll}
\hline ID & $\begin{array}{l}\Delta \mathbf{K V} @ \mathbf{4 0}^{\circ} \mathbf{C} \\
{[\%]}\end{array}$ & $\begin{array}{l}\Delta \text { Soot-in-oil (BTSA) } \\
{[\%]}\end{array}$ & $\begin{array}{l}\Delta \text { Soot-in-oil (FTIR) } \\
{[\%]}\end{array}$ & $\begin{array}{l}\Delta \text { Fuel in oil (FTIR) } \\
{[\%]}\end{array}$ & $\begin{array}{l}\text { HC in exhaust } \\
{[\mathrm{g} / \mathrm{h}]}\end{array}$ \\
\hline 3400@13_EGR & 2.00 & 7.11 & 41.62 & 13.21 \\
2000@2_SoI main & -6.00 & -0.57 & 9.13 & 22.28 \\
2000@2_SoI & -0.92 & 8.53 & 32.93 \\
2000@2_Fuel & -6.50 & -6.50 & 2.70 & 2.97 & 15.07 \\
\hline
\end{tabular}

Figure 13: Variation of kinematic viscosity at $40^{\circ} \mathrm{C}$, soot-in-oil content, fuel dilution and $\mathrm{HC}$ in the exhaust for all modified tests.

An exhaustive experimental validation of CFD simulations was previously performed, including both qualitative and quantitative comparisons, to assure the reliability of the numerical results. Two distinct operating conditions were selected, being sufficiently representative of both combustion modes studied: point $3400 @ 13$ for conventional combustion and 2000@2 for DPF regeneration mode. Both points have showed the most extreme situations in terms of soot generation and soot-in-oil content.

The usual validation methodology based on reproducing the in-cylinder pressure trace averaged from a given number of experimentally recorded cycles is presented in Fig. 14. In this figure, a comparison between HRR traces, soot emissions and soot-in-oil content has been also included. In general, a good estimation of the in-cylinder pressure is achieved in both operating conditions. Only a slight overestimation is observed during the expansion stroke in the DPF regeneration point. Regarding the HRR trends, a good match between experimental and simulated data is also obtained. Nonetheless, the post injection behaviour is not completely captured. Although the amount of energy released during this injection event is similar in the experiment and in the simulation, HRR trace is more progressive in the simulation. Thereby, combustion is lengthened causing the pressure overestimation already seen in the last stage of the expansion stroke.

In addition to this qualitative comparison, soot emissions and soot-in-oil content were also assessed. In the same Fig. 14, it can be observed that both parameters predictions are quite reasonable. In these simulations soot levels were calibrated by adjusting the constants of the Hiroyasu model 60 to reach comparable levels of soot at the end of the combustion cycle. Moreover, the suitability of the thermophoretic sub-model for predicting the $\mathrm{SiO}$ content has been proven since $\mathrm{SiO}$ levels are in-range with experimental data. Point $3400 @ 13$ show comparable values whereas point 2000@2 predict zero-levels as for the experiments.

With this baseline model configuration, additional simulations were performed to check the sensitivity of the model to predict the trends observed in the experiments. In this way, modifications made in section 5.3 to the operating settings were also applied to the simulations. Therefore, the EGR rate and the main injection timing were changed according to Table 3. 

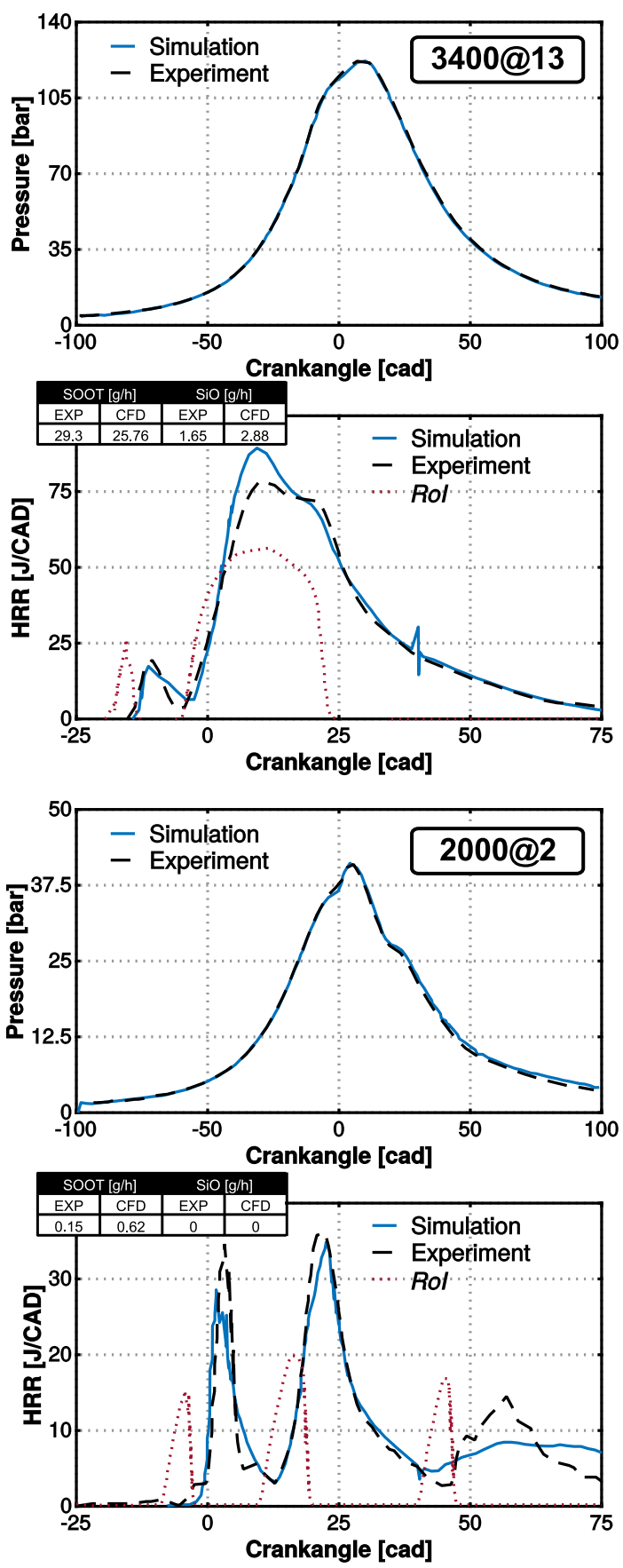

Figure 14: Comparison between measured and CFD calculated results of tests 3400@13 and 2000@2. In-cylinder pressure and HRR traces are plotted for both engine tests. The rate of injection (RoI) is also included for reference.

Results were analysed through the two parameters shown in Fig. 15. In this figure, the soot content in the exhaust/oil are compared for both experimental and numerical approaches used in this work, thereby giving an overview of the trends followed by both approaches. As can be seen, trends are reasonably captured by the model when the EGR rate and the main injection timing are modified at the reference point 3400@13. In these cases, soot contents change in the same way. Soot emissions and the $\mathrm{SiO}$ content increase when the EGR rate is incremented. By contrast, both parameters decrease when delaying the main injection timing. 
Regarding the DPF regeneration point, similar encouraging results are obtained. Generally, soot in the exhaust is correctly estimated despite some discrepancies observed when modifying the fuel mass injected during the post injection. Nevertheless, the reliability of the model to predict $\mathrm{SiO}$ is evident since no $\mathrm{SiO}$ content is obtained neither in experiments nor in simulations.

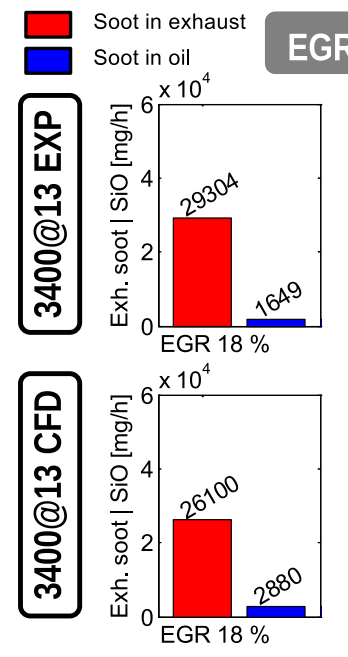

Post fuel mass
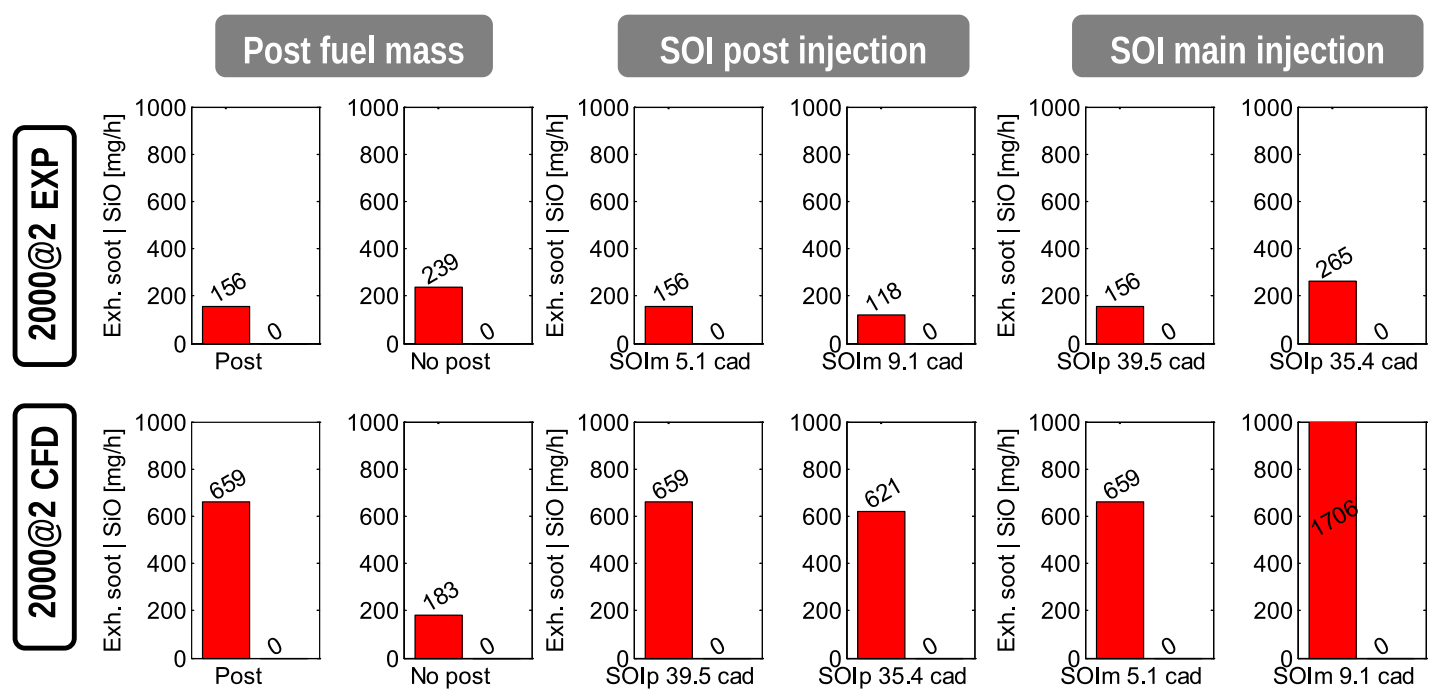

\section{GR}

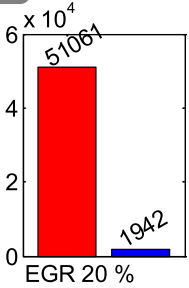

$\times 10^{4}$

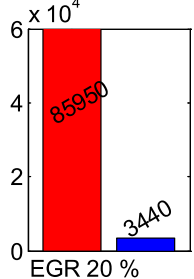

\section{SOI}
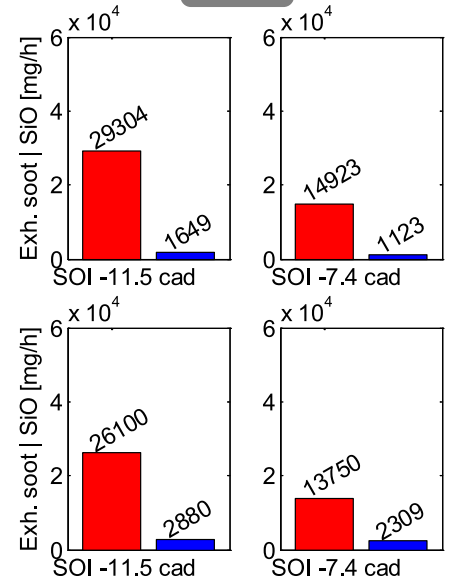

Figure 15: Validation of experiment trends. Soot content in the exhaust and diluted in the engine oil are plotted to compare experimental and simulation results.

\subsubsection{Analysis of the conventional combustion mode}

After the model validation, where it has been proven that the CFD model is suitable for predicting the $\mathrm{SiO}$ content in most of the situations considered in this paper, the CFD solution can be used to visualize those elusive phenomena impossible to be seen experimentally.

In this section, the numerical model is used to provide more insight about the soot generation and $\mathrm{SiO}$ mechanisms when operating under reference conditions. In particular, this analysis was done for the validated point 3400@13. The effects of the EGR and the $\mathrm{SoI}_{\text {main }}$ modifications were studied.

A series of snapshots were conscientiously chosen and plotted together in Fig. 16 for analysing the soot generation within the combustion chamber. They were specifically selected considering the final stage of combustion where the soot is mainly generated. 


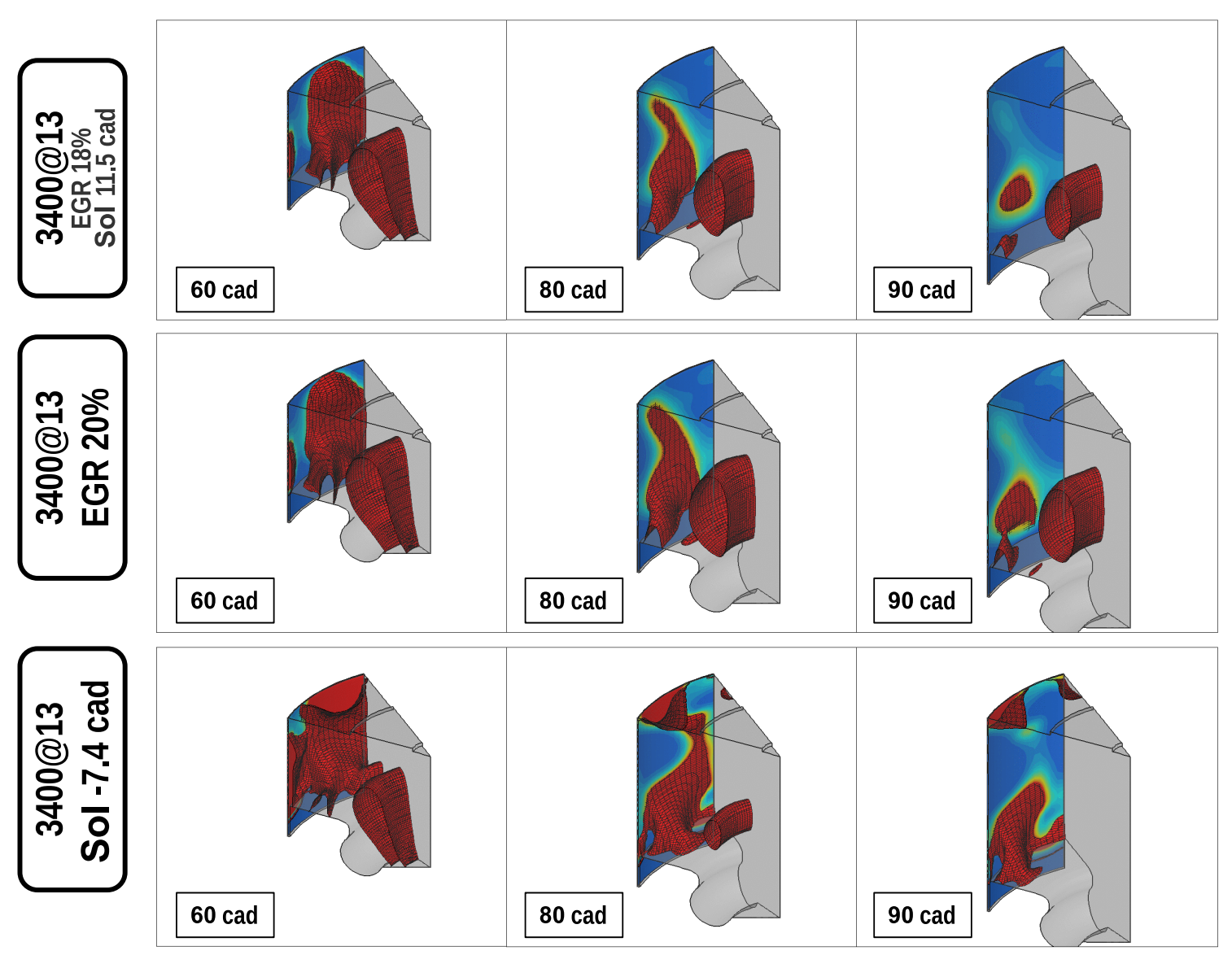

Figure 16: Soot generation and soot-in-oil visualization along the combustion process of the reference point $3400 @ 13$.

In this figure, soot particles at the cylinder wall are depicted using a contour plot. The colour scale was carefully fixed for a proper visualization of the spatial patterns of soot in contact with the wall. In addition, all soot particles location are also visualized by clipping the soot concentration at a given representative value (brown iso-surfaces).

Focusing on the first two rows of snapshots, where the effect of an increased EGR is shown, we can see that soot iso-surfaces are very similar in both cases. Indeed, it is only possible to observe significant differences at the end of the expansion stroke $(90 \mathrm{cad})$. In both cases there are two differentiated areas where soot is being generated: one located close to the centre of the combustion chamber within the piston bowl, and other located in the squish region in contact with the cylinder wall. It is observed that the size of soot iso-surfaces is larger in the case with increased EGR. This is consistent with the worsened mixing conditions achieved when increasing the EGR, which leads to a higher soot generation rate. More soot close to the wall increases the soot deposition and the $\mathrm{SiO}$ content as well. This is especially evident in the last snapshot: the iso-surface of soot is larger when operating with $20 \%$ of EGR.

Inspecting the effect of the main injection timing (rows 1 and 3 of Fig. 16), clear differences can be found between both cases. Although the two-region pattern present in the reference case (3400@13) is somehow maintained during in the first snapshots of case 3400@13_SoI main, it remarkably changes in the last snapshot. The soot located at the centre of the chamber spreads, resulting in a completely different pattern that helps to reduce the amount of $\mathrm{SiO}$. 


\subsubsection{Analysis of the PRF regeneration mode}

The study presented in the previous section is extended here to the DPF regeneration point 2000@2. As commented above, this is a very particular point in which $\mathrm{SiO}$ shows no sensitivity to any of the modifications made in the operating settings.

Snapshots depicted in Fig. 17 show the instants between the start of the main injection and the end of combustion. As in the previous section, the same representation is used to visualize both the soot generated by combustion and the soot in contact with oil film on the cylinder wall. In addition, unburned HC are also included for comparison using a similar visualization.

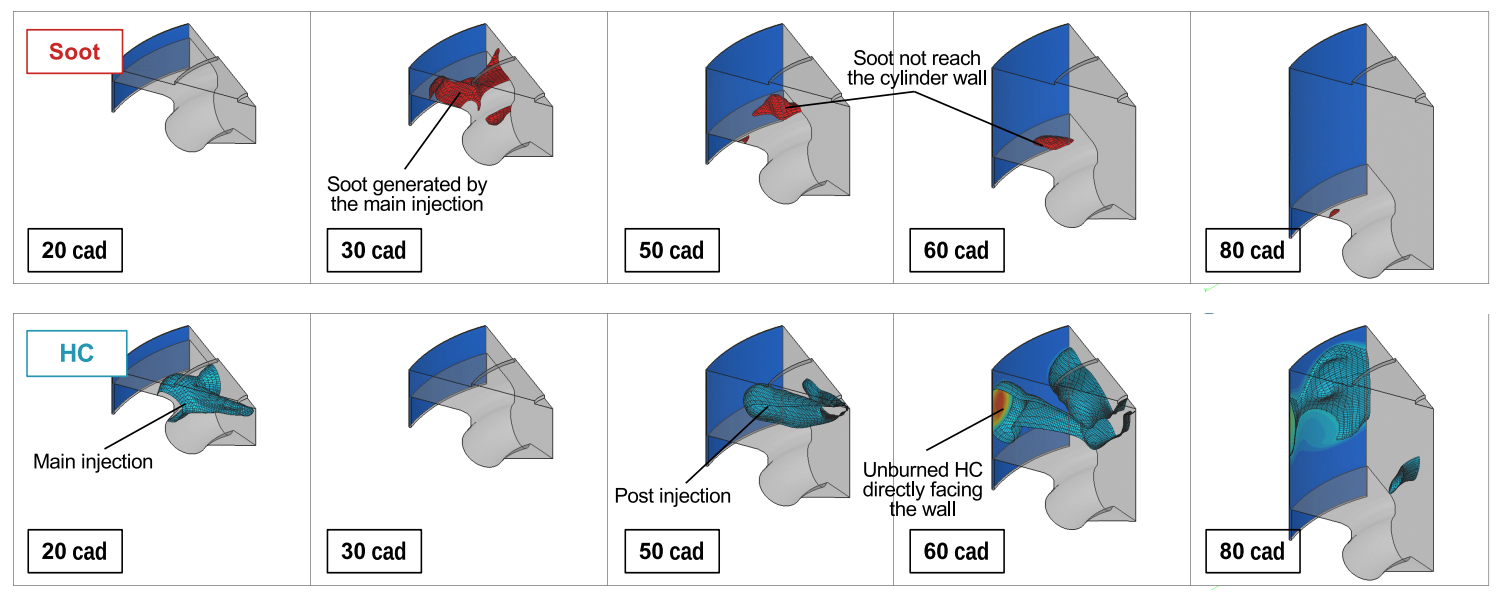

Figure 17: Soot generation and soot-in-oil visualization along the combustion process of the reference point $2000 @ 2$.

It can be seen from this sequence how the main injection is fully burned between snapshot 1 and 2 (20-30 cad). Note that HC iso-surface completely disappears in snapshot 2 . As a result, the generated soot is located at the squish region but never reaches the cylinder wall (40-60 cad), avoiding the possible $\mathrm{SiO}$ mixing. Snapshot 3 shows the instant in which the post injection is taking place, meanwhile iso-surfaces of soot concentration become smaller due to the soot particles diffusion. After the post injection, inadequate thermodynamic conditions during the expansion stroke compromise the fuel burning and consequently most of the fuel remains inert once the injection is finished whereas no soot is generated (60-50 cad). Moreover, the momentum induced by the spray lead the unburned HC directly to the cylinder wall (see snapshot 4). Lastly, the final snapshot shows that most of these HC stay in contact with the oil even until exhaust valves are opened, thereby increasing the oil dilution significantly as the experiments have shown.

\section{Summary and conclusions}

In view of the potential engine failures due to the oil degradation, this paper assess the effects of emissionscontrol strategies on the $\mathrm{SiO}$ content and fuel dilution of a medium-duty diesel engine. A combination of experiments and numerical simulations are used not only to determine the effect of post-treatment strategies and their consequences in the tribological properties of the engine oil, but also contributing to the understanding of dilution and $\mathrm{SiO}$ deposition mechanisms.

Both approaches, experimental and numerical modelling, have been widely validated. In experiments, several techniques - including both on-line measurements and lab analyses - have been compared, showing a good coherence between all of them. In CFD simulations, a good correlation (qualitative) with the experiments has been obtained in the traditional engine parameters as well as in $\mathrm{SiO}$ content predictions. 
Results from experiments revealed that $\mathrm{SiO}$ content is not directly correlated with the amount of soot generated during combustion. High engine speeds are the most critical conditions, specially when operating at high loads. However, fuel dilution is more apparent during the DPF regeneration mode where the post injection event is excessively delayed towards the expansion stroke. These trends have been demonstrated by both on-line measurements (BTSA) and oil analyses performed in the laboratory (FTIR and KV analysis).

In addition, experiments also showed the influence of the main emission-control strategies in the oil quality deterioration. The use of residual gases to decrease the charge reactivity tends to increase the soot generation as well as the amount of $\mathrm{SiO}$. In a similar way, increasing the injection pressure also increase the presence of soot in the exhaust and in the oil. The timing of the injections also plays a relevant role in the engine oil degradation. The amount of soot is reduced in both exhaust and engine oil when delaying the main injection. However, the timing of the post injection during the DPF regeneration has a limited impact. Only a certain increment of the $\mathrm{SiO}$ content with a constant level of soot generated is observed at medium load and low engine speed. Similarly, the injected fuel mass during the post injection event does not have any remarkable effect.

Advantage has been taken from numerical results to establish the relation between the soot generation and its subsequent deposition in the engine oil. Indeed, simulations allowed visualization of where the soot is generated and how it evolves inside the combustion chamber due to convection and diffusion mechanisms. In this way, it has been determined that the spatial pattern of soot is not altered when increasing the EGR rate but the overall soot level and $\mathrm{SiO}$ content is increased. On the contrary, delaying the main injection timing causes a completely different spatial pattern of soot that leads to a decreased $\mathrm{SiO}$ content. Finally, it has been demonstrated that late post injections do not contribute to either the soot generation or the SiO. Poor thermodynamic conditions during the expansion stroke hinder the complete burning of the fuel, avoiding the soot generation while leading the unburned $\mathrm{HC}$ directly to the cylinder wall.

Further improvements are nonetheless needed to enhance the model predictability in all situations. This is, when considering additional operating points while modifying the injection pressure and the post injection mass quantity.

\section{Acknowledgments}

A. García-Barberá is partially supported through the Programa Nacional de Formación de Recursos Humanos de Investigación of Spanish Ministerio de Ciencia e Innovación [grant number BES-2016-078073].

The authors also wish to thank Dr. José M. Pastor for his inestimable assistance in the CFD model implementation and data post-processing. 


\section{References}

[1] A. C. Lloyd, T. A. Cackette, Diesel engines: environmental impact and control, Journal of the Air \& Waste Management Association 51 (6) (2001) 809-847.

[2] M. Fiebig, A. Wiartalla, B. Holderbaum, S. Kiesow, Particulate emissions from diesel engines: correlation between engine technology and emissions, Journal of Occupational Medicine and Toxicology 9 (1) (2014) 6.

[3] C. Directive, 91/441/EEC of 26 June 1991 amending Directive 70/220, EEC on the approximation of the laws of the Member States relating to measures to be taken against air pollution by emissions from motor vehicles.

[4] E. Directive, 98/69/EC of the European Parliament and of the Council of 13 October 1998 relating to measures to be taken against air pollution by emissions from motor vehicles and amending Council Directive 70/220/EEC, Official Journal of the European Communities L 350 (28) (1998) 12.

[5] E. Directive, Directive 2005/55/EC of the European Parliament and of the Council of 28 September 2005 on the approximation of the laws of the Member States relating to the measures to be taken against the emission of gaseous and particulate pollutants from compression-ignition engines for use in vehicles, and the emission of gaseous pollutants from positive-ignition engines fuelled with natural gas or liquefied petroleum gas for use in vehicles, Official Journal of the European Communities L 275 (2005) 1-163.

[6] E. Directive, Regulation (EC) No 715/2007 of the European Parliament and of the Council of 20 June 2007 on type approval of motor vehicles with respect to emissions from light passenger and commercial vehicles (Euro 5 and Euro 6) and on access to vehicle repair and maintenance information, Official Journal of the European Communities L 171 (2007) 1-16.

[7] E. Regulation, Regulation (EC) No 595/2009 of the European Parliament and of the Council of 18 June 2009 on typeapproval of motor vehicles and engines with respect to emissions from heavy duty vehicles (Euro VI) and on access to vehicle repair and maintenance information and amending Regulation (EC) No 715/2007 and Directive 2007/46/EC and repealing Directives 80/1269/EEC, 2005/55/EC and 2005/78/EC, Official Journal of the European Communities L 188.

[8] Z. Jinghua, H. Wei, L. Xuejun, X. Fangxi, J. Li, Study about effects of EGR and injection parameters on the combustion and emissions of high-pressure common-rail diesel engine, Industrial Mechatronics and Automation (ICIMA), 2010 2nd International Conference on 1 (2010) 290-294.

[9] D. Agarwal, S. K. Singh, A. K. Agarwal, Effect of Exhaust Gas Recirculation (EGR) on performance, emissions, deposits and durability of a constant speed compression ignition engine, Applied Energy 88 (8) (2011) 2900-2907.

[10] P. S. Divekar, X. Chen, J. Tjong, M. Zheng, Energy efficiency impact of EGR on organizing clean combustion in diesel engines, Energy Conversion and Management 112 (2016) 369-381.

[11] T. Lattimore, C. Wang, H. Xu, M. L. Wyszynski, S. Shuai, Investigation of EGR effect on combustion and PM emissions in a DISI engine, Applied Energy 161 (2016) 256-267.

[12] Z. Gao, W. Schreiber, The effects of EGR and split fuel injection on diesel engine emission, International Journal of Automotive Technology 2 (4) (2001) 123-133.

[13] X. Li, Z. Xu, C. Guan, Z. Huang, Impact of exhaust gas recirculation (EGR) on soot reactivity from a diesel engine operating at high load, Applied Thermal Engineering 68 (1) (2014) 100-106. doi:10.1016/j.applthermaleng.2014.04.029

[14] S. K. Singh, A. K. Agarwal, M. Sharma, Experimental investigations of heavy metal addition in lubricating oil and soot deposition in an EGR operated engine, Applied Thermal Engineering 26 (2) (2006) 259-266. doi:10.1016/j applthermaleng.2005.05.004.

[15] S. George, S. Balla, M. Gautam, Effect of diesel soot contaminated oil on engine wear, Wear 262 (9-10) (2007) $1113-1122$.

[16] J. Fang, Z. Meng, J. Li, Y. Pu, Y. Du, J. Li, Z. Jin, C. Chen, G. G. Chase, The influence of ash on soot deposition and regeneration processes in diesel particular filter, Applied Thermal Engineering 124 (2017) 633-640. doi:10.1016/j applthermaleng.2017.06.076.

[17] H. Fujita, H. Spikes, The influence of soot on lubricating films, Tribology Series 43 (2004) 37-43.

[18] A. Behn, M. Feindt, G. Matz, S. Krause, M. Gohl, Fuel Transport across the Piston Ring Pack: Measurement System Development and Experiments for Online Fuel Transport and Oil Dilution Measurements, SAE Technical Paper (2015-242534).

[19] S. Aldajah, O. Ajayi, G. Fenske, I. Goldblatt, Effect of exhaust gas recirculation (EGR) contamination of diesel engine oil on wear, Wear 263 (1-6) (2007) 93-98.

[20] A. Dennis, C. P. Garner, D. Taylor, The effect of EGR on diesel engine wear, SAE Technical Paper (1999-01-0839).

[21] C. Y. Robert, S. M. Shahed, Effects of injection timing and exhaust gas recirculation on emissions from a DI diesel engine, SAE Technical Paper (811234).

[22] J. Heredia-Cancino, M. Ramezani, M. Álvarez Ramos, Effect of degradation on tribological performance of engine lubricants at elevated temperatures, Tribology International 124 (2018) 230-237. doi:10.1016/j.triboint.2018.04.015

[23] J. A. Mc Geehan, W. Alexander, J. Ziemer, S. Roby, J. Graham, The pivotal role of crankcase oil in preventing soot wear and extending filter life in low emission diesel engines, SAE Technical Paper (1999-01-1525).

[24] F. M. Salehi, A. Morina, A. Neville, The effect of soot and diesel contamination on wear and friction of engine oil pump, Tribology International 115 (2017) 285-296. doi:10.1016/j.triboint.2017.05.041

[25] J.-R. Lenk, L. Meyer, I. S. Provase, Oil Dilution Model for Combustion Engines-Detection of Fuel Accumulation and Evaporation, SAE Technical Paper (2014-36-0170).

[26] M. Gautam, K. Chitoor, M. Durbha, J. C. Summers, Effect of diesel soot contaminated oil on engine wear-investigation of novel oil formulations, Tribology International 32 (12) (1999) 687-699.

[27] M. Wattrus, Fuel property effects on oil dilution in diesel engines, SAE International Journal of Fuels and Lubricants 6 (2013-01-2680) (2013) 794-806.

[28] M. Andreae, H. Fang, K. Bhandary, Biodiesel and fuel dilution of engine oil, SAE Technical Paper (2007-01-4036). 
[29] D. Ljubas, H. Krpan, I. Matanović, Influence of engine oils dilution by fuels on their viscosity, flash point and fire point, Nafta: exploration, production, processing, petrochemistry 61 (2) (2010) 73-79.

[30] S. Antusch, M. Dienwiebel, E. Nold, P. Albers, U. Spicher, M. Scherge, On the tribochemical action of engine soot, Wear $269(1-2)(2010) 1-12$.

[31] H. Sato, N. Tokuoka, H. Yamamoto, M. Sasaki, Study on wear mechanism by soot contaminated in engine oil (first report: relation between characteristics of used oil and wear), SAE Technical Paper (1999-01-3573).

[32] D. Green, R. Lewis, R. Dwyer-Joyce, Wear effects and mechanisms of soot-contaminated automotive lubricants, Proceedings of the Institution of Mechanical Engineers, Part J: Journal of Engineering Tribology 220 (3) (2006) 159-169.

[33] Z. Tang, Z. Feng, P. Jin, X. Fu, H. Chen, The soot handling ability requirements and how to solve soot related viscosity increases of heavy duty diesel engine oil, Industrial Lubrication and Tribology 69 (5) (2017) 683-689.

[34] S. George, S. Balla, V. Gautam, M. Gautam, Effect of diesel soot on lubricant oil viscosity, Tribology International 40 (5) (2007) 809-818.

[35] P. Ryason, I. Chan, J. Gilmore, Polishing wear by soot, Wear 137 (1) (1990) 15-24.

[36] F. M. Salehi, A. Morina, A. Neville, The effect of soot and diesel contamination on wear and friction of engine oil pump, Tribology International 115 (2017) 285-296.

[37] A. Broatch, P. Olmeda, X. Margot, J. Gomez-Soriano, Numerical simulations for evaluating the impact of advanced insulation coatings on $\mathrm{H} 2$ additivated gasoline lean combustion in a turbocharged spark-ignited engine, Applied Thermal Engineering 148 (2019) 674-683. doi:10.1016/j.applthermaleng.2018.11.106

[38] A. Broatch, R. Novella, J. García-Tíscar, J. Gomez-Soriano, On the shift of acoustic characteristics of compression-ignited engines when operating with gasoline partially premixed combustion, Applied Thermal Engineering 146 (2019) $223-231$. doi:10.1016/j.applthermaleng.2018.09.089.

[39] M. Lapuerta, O. Armas, J. J. Hernández, Diagnosis of DI Diesel combustion from in-cylinder pressure signal by estimation of mean thermodynamic properties of the gas, Applied Thermal Engineering 19 (5) (1999) 513-529. doi:10.1016/ S1359-4311(98)00075-1.

[40] F. Payri, S. Molina, J. Martín, O. Armas, Influence of measurement errors and estimated parameters on combustion diagnosis, Applied Thermal Engineering 26 (2-3) (2006) 226-236. doi:10.1016/j.applthermaleng.2005.05.006

[41] R. Christian, F. Knopf, A. Jasmek, W. Schindler, A new method for the filter smoke number measurement with improved sensitivity, MTZ 54 (1993) 16-22.

[42] X. Zhu, C. Zhong, J. Zhe, Lubricating oil conditioning sensors for online machine health monitoring - a review, Tribology International 109 (2017) 473-484. doi:10.1016/j.triboint.2017.01.015

[43] ASTM D5967-17 Standard Test Method for Evaluation of Diesel Engine Oils in T-8 Diesel Engine, Tech. rep., ASTM International (2017) URL https://doi.org/10.1520/D5967-17

[44] A. Bredin, A. V. Larcher, B. J. Mullins, Thermogravimetric analysis of carbon black and engine soot. Towards a more robust oil analysis method, Tribology international 44 (12) (2011) 1642-1650.

[45] ASTM D7844-18 Standard Test Method for Condition Monitoring of Soot in In-Service Lubricants by Trend Analysis using Fourier Transform Infrared (FT-IR) Spectrometry, Tech. rep., ASTM International (2018). URL https://doi.org/10.1520/D7844-18

[46] User's manual: Bench Top Soot Analyzer, Analytical Engineering, Inc. URL http://www.aei-tech.com/products/btsa/

[47] ASTM D3524-14 Standard Test Method for Diesel Fuel Diluent in Used Diesel Engine Oils by Gas Chromatography Tech. rep., ASTM International (2014). URL https://doi.org/10.1520/D3524

[48] ASTM D7593-14 Standard Test Method for Determination of Fuel Dilution for In-Service Engine Oils by Gas Chromatography Tech. rep., ASTM International (2014).

URL https ://doi .org/10.1520/D7593-14

[49] STAR-CD. Version 4.22, Methodology (2016).

[50] A. Broatch, X. Margot, R. Novella, J. Gomez-Soriano, Impact of the injector design on the combustion noise of gasoline partially premixed combustion in a 2-stroke engine, Applied Thermal Engineering 119 (2017) 530-540. doi:10.1016/j applthermaleng.2017.03.081.

[51] A. Broatch, R. Novella, J. García-Tíscar, J. Gomez-Soriano, Potential of dual spray injectors for optimising the noise emission of gasoline partially premixed combustion in a 2-stroke hsdi ci engine, Applied Thermal Engineering 134 (2018) 369-378. doi:10.1016/j.applthermaleng.2018.01.108

[52] V. Yakhot, S. Orszag, Renormalization group analysis of turbulence., Journal of Scientific Computing 1 (1) (1986) 3-51. doi:10.1007/BF01061452

[53] C. Angelberger, T. Poinsot, B. Delhay, Improving near-wall combustion and wall heat transfer modeling in SI engine computations, SAE Technical Paper (2003-01-0542). doi:10.4271/972881.

[54] R. I. Issa, Solution of the implicitly discretised fluid flow equations by operator-splitting, Journal of Computational Physics 62 (1986) 40-65. doi:10.1016/0021-9991(86)90099-9

[55] O. Colin, A. Benkenida, The 3-zones extended coherent flame model (ECFM3Z) for computing premixed/diffusion combustion, Oil \& Gas Science and Technology 59 (6) (2004) 593-609.

[56] K. Huh, A phenomenological model of diesel spray atomization, Proc. of The International Conf. on Multiphase Flows' 91-Tsukuba.

[57] R. D. Reitz, R. Diwakar, Structure of high-pressure fuel sprays, SAE Technical Paper (870598). 
[58] C. Habchi, F. A. Lafossas, P. Béard, D. Broseta, Formulation of a one-component fuel lumping model to assess the effects of fuel thermodynamic properties on internal combustion engine mixture preparation and combustion, SAE Technical Paper (2004-01-1996).

[59] A. Karlsson, I. Magnusson, M. Balthasar, F. Mauss, Simulation of soot formation under diesel engine conditions using a detailed kinetic soot model, SAE Technical Paper (981022).

[60] H. Hiroyasu, T. Kadota, Models for Combustion and Formation of Nitric Oxide and Soot in Direct Injection Diesel Engines, SAE Technical Paper (760129). doi:10.4271/760129.

[61] J. F. Wiedenhoefer, R. D. Reitz, Multidimensional modeling of the effects of radiation and soot deposition in heavy-duty diesel engines, SAE Technical Paper (2003-01-0560).

[62] L. Dahlén, On applied CFD and model development in combustion systems development for DI diesel engines: Prediction of soot mediated oil thickening, Ph.D. thesis, Royal Institute of Technology, Stockholm, Sweden (2002). 